\title{
Electronic Commerce: Factors Involved in its Adoption from a Bibliometric Analysis
}

\section{Eliana Villa ${ }^{1,2}$, Luis Ruiz ${ }^{3}$, Alejandro Valencia ${ }^{4}$ and Edgar Picón ${ }^{5}$}

\footnotetext{
${ }^{1}$ Universidad Nacional de Colombia - Sede Medellín, Doctoral Student, Medellín, Colombia, emvilla@unal.edu.co

2 Instituto Tecnológico Metropolitano ITM, Departamento de Ciencias Administrativas, Medellín, Colombia, elianavilla@itm.edu.co

3 Instituto Tecnológico Metropolitano ITM, Departamento de Ciencias Administrativas, Medellín, Colombia luisruiz@itm.edu.co

${ }^{4}$ Instituto Tecnológico Metropolitano ITM, Departamento de Ciencias Administrativas, Medellín, Colombia, jhoanyvalencia@itm.edu.co

${ }^{5}$ Universidad de Antioquia, Escuela de Idiomas, Medellín, Colombia, edgar.picon@udea.edu.co
}

Received 18 August 2016; received in revised form 22 August 2017; accepted 25 August 2017

\begin{abstract}
This article presents findings of a study that aimed to identify key factors in the adoption of e-commerce. The study involved a bibliometric analysis of statistical information from 408 scientific publications related to the theme, registered in the Scopus database, through a structured search equation. The collected records were used to calculate bibliometric indicators of quantity, quality and structure. Additionally, an analysis of increasing, decreasing, and emerging thematics was carried out to identify the topics of greatest interest on this subject. Findings indicate that this is a prolific research field, in which the fastest growing topic is the study of e-commerce adoption in small and medium sized enterprises in emerging economies. The analysis also revealed the current use of new models to evaluate adoption factors. That is the case of the Technology Organization Environment Framework used as an alternative to the Technology Acceptance Model--which remains the most widely used. Likewise, Structural Equation Analysis was found to be one of the most frequently used options for statistical analysis in the publications studied. A research agenda intending to contribute with directions for further research in the area is presented at the end of the article.
\end{abstract}

Keywords: Adoption factors, Bibliometric analysis, Internet transactions, Electronic commerce, Research trends 


\section{Introduction}

As part of the tools of the new millennium to generate competitiveness in organizations and foster the use of information and communication technologies ICT, electronic commerce or e-commerce emerged. This type of trade has been increasing over time and more and more organizations are generating these communication channels with the customer to enhance trade relations [85]. Overall, e-commerce is changing the nature of trade worldwide; however, this revolution is developing at different rates in different areas of the planet [208]. At present, its most relevant influence is taking place in Asia, USA and Northern Europe [20], [144], [206].

In addition to its outstanding advance in developed countries, e-commerce is being used more and more in emerging countries where the level of its acceptance is rapidilly increasing. Due to the changes occurring in the way shopping is being carried out worldwide, commerce has passed from happening through direct contact between people to taking place through intangible means and a variety of alternatives, offered based on the customer's needs, in order to obtain goods. As a result, organizations that have traditionally offered products for sale through traditional channels, are finding better alternatives to make handsome profits through virtual ones.

Understanding how e-commerce technology adoption behaves in the social and economic contexts in which it has not been studied, is of paramount importance to contribute to future research in this field, as well as to provide the business sector interested with channels different from the traditional ones to enter new markets. Nonetheless, given the sociocultural differences existing among developed and emerging nations, and due to every process of adoption responds to different cultural, social, and political dynamics, the study of technology acceptance in diverse contexts becomes challenging. Consequently, this study intends to examine the approaches, topics, and variables that have emerged in the exploration of e-commerce technology adoption in emerging countries in order identify the existing factors that influence such adoption in different economic, social, and cultural contexts.

Decisions about adopting technologies like e-commerce are influenced by aspects such as the relative novelty of these types of innovations and the greater uncertainty associated to the implementation of new technologies at large. In this regard, several studies have inquired about the factors that influence e-commerce application and found that they vary in terms of object of study, as well as the social, cultural, and economic contexts where this technology is adopted. Such variety of influencing factors has hindered establishing generic models to permit an adequate evaluation of the issue. Accordingly, this research study sought to examine and discuss trends and developments in the analysis of the factors involved in the adoption of e-commerce, led by two main research questions: What are the tendencies in the study of e-commerce adoption factors? What are the most researched topics in this field of knowledge?

The causes that motivate people and enterprises to find out the factors that move the business sector to adopt electronic commerce are diverse. In this regard, [11] claims that the most important benefit that promotes e-commerce adoption in the business sector is the generation of customer trust, while its most significant barrier is lack of electronic payment systems. On the other hand, [13] state that e-commerce has become a very important opportunity among small and medium-sized enterprises (SMEs). SMEs executives have realized that e-commerce allows them to introduce innovation in the market and increase their competitive advantage in a more efficient way.

Regarding pragmatic motivations, an adecuated identification of the factors involved in the adoption of e-commerce at the time of implementing it within a given enterprise context permits incrementing the productivity and profits of corporations and facilitates the generation of strategies consistent with the needs of the implementation environment. Consequently, awareness of the factors that influence e-commerce adoption will make its implementation easier and more likely to be successful for an enterprise. Carrying out research about this matter is thus very important as it would enable the assignation of resources on the factors and variables identified as a priority at the occasion of implementing e-commerce [97], [129], [132].

Regarding the method, bibliometrics have been chosen because it allows a holistic view of the researched context of a specific theme [154]; providing significant data about topics, authors, journals, countries and the most productive and influencing institutions; and supplying information about current trends in the issue and its impact on a given context [58]. Therefore, bibliometric studies are considered to offer valuable starting points for new research on emergent themes [67]. Considering the qualities of bibliometrics, we have chosen this research method to study the factors of e-commerce acceptance. We considered that it would enable suitable access to the research context of the topic, permitting the identification of the main approaches, and the authors that have made the most outstanding contributions in the generation of new models and methodologies to study it.

A bibliometric study was thus utilized in this analysis as a tool to facilitate the identification of tendencies in the adoption of e-commerce. Several indicators for the analyzed field were defined and a dynamic of keywords that permitted the identification and selection of 408 journal articles was developed. The inquiry led to the revision of the main publications on the topic, with the intention of having a holistic perspective of the factors that are most frequently associated to the adoption of e-commerce. We expect that such perspective will serve as a referent for new studies on the evaluation of adoption factors, giving access to a richer number of theoretical sources, permitting an integral vision of the results 
from previous studies, and allowing the construction of better research designs that could focus on the issue with greater theoretical end empirical validity.

The paper is structured as follows: Drawing on the work of various authors, the first section presents a conceptual framework that elaborates on the most important concepts related to electronic commerce, points out some milestones in its historical development, highlights its importance, and exposes the factors that promote or inhibit its adoption. In a second section, the methodology used for bibliometric analysis is described. In a third section, the obtained results are laid out along with their interpretation. Finally, conclusions and limitations of the study are presented followed by a research agenda.

\section{Conceptual Background}

This section presents the conceptual framework that supports the bibliometric analysis used in the research methodology. This framework introduces the conceptualization of e-commerce, presents some milestones of development, and highlights its importance in strengthening supplier-customer relations in today's organizations.

\subsection{Electronic Commerce (E-Commerce)}

Electronic commerce has been defined as a useful tool to reduce the economic gap between countries [149] and as a channel to deliver products and services through the Internet. However, although it has become a source of competitive advantage due to the possibilities offered to both buyers and sellers, its use, especially in emerging economies, is limited [52]. The main advantage mentioned by the authors in the use of electronic commerce relates to the opportunity that it provides for companies to expand their number of customers [18] and its potential to become a medium to boost micro, small and medium sized enterprises--which represent a source of economic growth for many countries [70], [102]. In the United States, for example, it has become a transactional medium used for business by nearly $40 \%$ of the third of the population [55]. In addition, e-commerce can transform business management and its potential affects sectors as diverse as telecommunications, finance, industry, trade, education, health and government [203].

According to several authors, e-commerce comprises any transaction made by means of electronic devices, which allows conducting business and transforms internal and external relationships to create value and exploit the market opportunities influenced by new rules of a connected economy. It allows the incorporation of all transactions of information, products, services or payment via electronic networks, and integrates solutions to any transaction via Internet--which is understood as the use of digital communication networks to facilitate the purchase and sale of any product or service [15], [41], [44], [46], [62], [93], [149], [151], [185], [186], [192], [195], [200], [201].

As a product of the convergence of information and communication technologies (ICT), e-commerce can be defined from many perspectives. In [135] the following definitions are set out:

1. From the perspective of communication, e-commerce is the delivery of information, products, services or payment made through telephone lines, computer networks or similar means.

2. From the perspective of business process, e-commerce is the application of technology to achieve automation of transactions or workflow.

3. From the perspective of service, e-commerce is a tool to achieve the objectives of the organization and the customer, and to properly manage costs significantly improving delivery times.

4. From an online perspective, e-commerce provides the ability to view and buy products and information from the Internet or other online services.

Since 1997, when the White House launched the Framework for Global Electronic Commerce, a perception of the need to implement suitable policies for the development and growth of digital systems necessary to strengthen the free exchange of goods, services and information via Internet emerged. In this regard, the referred framework sought to strengthen e-commerce through four general principles that aimed at adopting an unregulated approach that would prevent undue restrictions to electronic commerce. The private sector would ideally lead the process recognizing the qualities of the Internet to develop it on the basis of a global context [43]. Despite the fact that almost 20 years have passed since the adoption of the regulatory framework, electronic commerce has not yet developed as envisaged within the global context. As a consequence, developing countries have basically failed to adequately adopt ecommerce. However, research has been conducted to study the factors that enable and promote its adoption [19], [21], [27], [52], [76], [86], [93], [96], [99], [119], [149], [176], [179], [204], [207]. The existent literature has allowed conceptualizing e-commerce and typifying it according to some characteristics. Table 1 groups the categories and applications of e-commerce defined by different authors in the literature: 
Table 1: Classification of e-commerce transaction

\begin{tabular}{|c|c|c|}
\hline E-Commerce Category & Application and use & Author \\
\hline C2C (Customer to Customer) & $\begin{array}{l}\text { Transactions directly between consumers in } \\
\text { cyberspace. }\end{array}$ & [74], [87]. \\
\hline B2C (Business to Customer). & $\begin{array}{l}\text { Negotiation of products or services through } \\
\text { electronic advertising buy, sell and secure payment } \\
\text { systems between customers and organizations. }\end{array}$ & [87], [193]. \\
\hline B2B (Business to Business). & $\begin{array}{l}\text { It is the market transaction among businesses, } \\
\text { governments and other organizations in a reliable } \\
\text { way between them. }\end{array}$ & [115]. \\
\hline C2B (Customer to Business). & $\begin{array}{l}\text { It is the online transaction where consumers begin } \\
\text { the commercial operation with companies. }\end{array}$ & [32], [33], [87]. \\
\hline C2G (Customer to Government). & $\begin{array}{l}\text { Online interaction where feedback is given to the } \\
\text { government by pressure groups or individual sites. }\end{array}$ & [60], [87], [150]. \\
\hline B2G (Business to Government). & $\begin{array}{l}\text { It is the online interaction where feedback is given } \\
\text { from business to government and non-governmental } \\
\text { organizations. }\end{array}$ & [60], [87], [150]. \\
\hline G2C (Government to Citizen). & $\begin{array}{l}\text { Online interaction through which the government } \\
\text { offers domestic services, such as local government, } \\
\text { national government information and tax information } \\
\text { transactions. }\end{array}$ & [30], [87]. \\
\hline Non-Business E-commerce. & $\begin{array}{l}\text { Organizations and academic institutions, civil, } \\
\text { religious, social and governmental organizations use } \\
\text { e-commerce to reduce costs of operations. }\end{array}$ & [193]. \\
\hline IntraBusiness ecommerce. & $\begin{array}{l}\text { All internal activities usually performed on an } \\
\text { Intranet. The activities are to sell corporate products } \\
\text { to employees, online training and cost reduction } \\
\text { activities. }\end{array}$ & [193]. \\
\hline $\begin{array}{l}\text { Administration-to-Business, A2B } \\
\text { E-commerce. }\end{array}$ & $\begin{array}{l}\text { It includes providing related information between } \\
\text { business and government procurement activities. }\end{array}$ & [183], [209]. \\
\hline $\begin{array}{l}\text { Administration-to-Citizen, A2C } \\
\text { E-commerce. }\end{array}$ & $\begin{array}{l}\text { Information to citizens or, at best, simple electronic } \\
\text { services such as downloading electronic forms. }\end{array}$ & [183]. \\
\hline
\end{tabular}

Source: prepared based on the sources mentioned in the table.

\subsection{Adoption Factors of E-Commerce}

E-Commerce is defined as a channel for any type of transaction, including offering products and services through the Internet, which, despite its advantages, has not yet managed to persuade a greater proportion of users to carry out transactions through this means of shopping [23]. In this regard, several studies have shown that the rate of consumer adoption for e-commerce is low in emerging economies and in micro, small and medium sized enterprises (SMEs) compared to developed countries [10], [18], [54], [70], [73], [99], [141]. Therefore, it has been considered important to conduct studies that examine the trends and developments in the identification of factors that encourage the adoption of e-commerce.

Academic and research studies have sought to explain the phenomenon of adoption of e-commerce with the goal of properly encouraging its use from various fields. For example, through the theory of diffusion of innovation, [65] an integrated model of the adoption of e-commerce for small enterprises in emerging economies was developed. Through this model, it was possible to identify determinant factors for the adoption of e-commerce involving perceived usefulness, perceived compatibility, perceived risks, perceived ease, and perceived complexity, which are defined in Table 2.

By the same token, [45] utilized the notion of orchestrating resources to study the process of adoption of e-commerce; findings from this study suggest that the prevailing competitive environment of each phase results in a capacity of specific coordination that develops through actions focused on resources. Another approach examined the dynamic competition between traditional retail companies and retailers on the Internet, using dynamic games theory [161], [101]. Other researchers have used the descriptive research design with statistical techniques to identify the same factors. As an example, a regression model was used in [21] to anticipate the adoption of e-commerce. In that study, all variables except the business experience of the company were found to have a significant contribution to explain the phenomenon

Regarding the focus of the papers analyzed, a study of issues such as gender to identify its impact on the adoption of e-commerce showed that it slightly influences its implementation in SMEs. [39]. A qualitative approach on the same subject showed that both organizational and environmental contexts and attributes of innovation influence the adoption of e-commerce [19]. Other studies on e-commerce investigated issues such as consumer behavior, analyzing the factors that influence the type of products / services purchased online [152] or cultural values of the individual behind 
the buyer's decision [38]. Finally, study [61] considered the performance of companies operating exclusively on the Internet, called e-companies or dotcoms, analyzing factors that are intrinsic to the Web site, such as accessibility, web presence and utility.

Table 2: Description of determinants of adoption of e-commerce, according to Elahi and Hassanzadeh [56]

\begin{tabular}{|l|l|}
\hline Factors & Description \\
\hline $\begin{array}{l}\text { Perceived } \\
\text { usefulness }\end{array}$ & $\begin{array}{l}\text { The extent to which an individual believes that using a particular system will improve his/her } \\
\text { performance in an activity [49]. It is also defined as user perception that the use of technology will } \\
\text { improve its performance over previous technologies [47], [48]. On the other hand, perceived } \\
\text { usefulness is the determinant component of cognitive behavioral intention, while attitude } \\
\text { represents the affective component [48]. For [197], perceived usefulness offers a more detail } \\
\text { explanation of why an adoption does not occur. Finally, perceived usefulness, a TAM factor, is } \\
\text { usually operationalized as an attitudinal variable in research [92]. }\end{array}$ \\
\hline $\begin{array}{l}\text { Perceived } \\
\text { compatibility }\end{array}$ & $\begin{array}{l}\text { The degree of consistency of the technology with values and beliefs, past and present, as well as } \\
\text { with the needs of adopters [80]. According to [167], it is related to the degree to which the adopter } \\
\text { is able to incorporate an innovation into his or her life. Perceived compatibility gives the idea of } \\
\text { how using a system fits with values and habits of the person at the time of completion of the } \\
\text { measure [49]. }\end{array}$ \\
\hline $\begin{array}{l}\text { Perceived } \\
\text { risks }\end{array}$ & $\begin{array}{l}\text { The fulfillment of the conditions of the transaction and online security [156]. It is one of the } \\
\text { essential theoretical supports when uncertainty is present, as characterized by the absence of } \\
\text { physical contact as in the case of online environments [146]. Liiterature has showed that } \\
\text { perceived risk influences the adoption of technologies [63], [146]. }\end{array}$ \\
\hline $\begin{array}{l}\text { Perceived } \\
\text { ease }\end{array}$ & $\begin{array}{l}\text { The extent to which the prospective user of a technology expects its use not to involve efforts } \\
\text { [49]. }\end{array}$ \\
\hline $\begin{array}{l}\text { Perceived } \\
\text { complexity }\end{array}$ & $\begin{array}{l}\text { The extra effort that comes with the application of an innovation, achieving minimum values when } \\
\text { the complication of its application is greater [166], [168]. Reason for which, the ease in handling a } \\
\text { computer system should positively influence the perception of their utility [6], [139], [177], [197]. }\end{array}$ \\
\hline Source: prepared based on the sources mentioned in the table.
\end{tabular}

On the other hand, [158] identified critical success factors for e-commerce including: adding value, focusing on a niche, expanding, maintaining flexibility and segmenting geographically, adopting the right technology to handle a critical perception, providing exceptional service, creating an effective connectivity, and understanding the culture of the Internet. Meanwhile, [50] studied internal and external organizational factors that may impact the use of Internet among SMEs, finding aspects that enable organizations to be self-efficient through technologies related to marketing use and perceived competitive pressure. The study carried out by [49] analyzed factors that prompt the adoption of e-commerce, examining the influence of perceived usefulness by consumers, and proposing the addition of five sources of income associated with the Internet: price advantage, variety of assortment, value of products, perceived convenience and access to information. In addition, [9] studied behavior in e-commerce adoption finding a significant correlation between perceived compatibility, perceived complexity, perceived observability, perceived uncertainty, among other factors analyzed.

Electronic commerce continues to be an emerging distribution channel even in developed countries. As a result, varied studies have been conducted to identify influencing factors in the adoption of e-commerce, and its implications for big contexts, first level economies, and large size enterprises. According to [168], a study conducted in Kuwait presents a model of online payment trust that reveals the impact of four external factors: personal innovation, tendency to trust, familiarity, and presence of third party seals over the intention of using an online payment through the mediation of three endogenous variable factors: pleasure, risk, and costumer trust. Costumer trust and pleasure are two important factors in the adoption of online payment. By the same token, [133] examine the factors that affect e-commerce adoption in the Arab states. Five countries are represented in this study: Saudi Arabia, Qatar, Kuwait, United Arab Emirates, and Yemen. Findings reveal that knowledge is the most important factor that influences the adoption of ecommerce mediating between costumer perception about the risk and their confidence to adopt it.

In fact, for large enterprises in the First World countries [165] analyzed the combined influence of environmental, technological, and organizational factors that determine e-commerce adoption. The study provides proof that competitive pressure discourages e-commerce adoption in the long term. The findings of this study also reveal that the development of consumption patterns, the technology availability of the market forces, the global reach of the enterprise, and its competences in innovation, continuously favor e-commerce adoption. Meanwhile, [59] showed that organizational, technical, and environmental barriers, as well as technology external factors have affected two initial variables of the Technology Acceptance Model (TAM) that includes perceived usefulness and facility. Likewise, the relations found in the TAM were confirmed including the impact of usefulness and perceived facility over attitude, the impact of attitude over intention, and the impact of intention over actual use.

The study conducted by [175] demonstrates that in developed countries security and privacy are the main aspects that encourage enterprises to adopt e-commerce channels, and consequently consumers to develop confidence in the digital environment. Electronic commerce will be useful in the current management practice, in the design of business policies and strategies, and in the exchange of information between organization executives and leaders. E-commerce 
nets are playing a fundamental role in online business and customers are more concerned about the ethical issues of electronic commerce, including security, privacy, and trust. The vast majority of public sectors

According to [205], in first world nations a better access to modern ICTs and the adoption of e-commerce applications stimulate bilateral commercial flows at various levels. The study points out efficient use of ICTs equipped with high speed Internet and safe servers as a crucial milestone to unblock e-commerce potential in developing countries. The public sector of depeloping countries acknowledges the importance of e-commerce for business to reach success, which highlights the importance of creating a supporting environment for the adoption and success of electronic commerce in the long term. In the same vein, [103] demonstrate that the public sector should particularly consider its commitment with e-commerce implementation, the generation of policies to regulate it, and the technological resources needed to implement it, as the main factors that mediate between e-commerce adequated use and its successful adoption.

\section{Materials and Methods}

The methodology for identifying factors of adoption of electronic commerce in this investigation consisted of a bibliometric analysis. Bibliometrics is conceived as the science that studies the trend of an area of knowledge or specific discipline through the computation and analysis of the facets of the written [157] communication and allow us to study science through aspects of quantity, quality, and scientific progress that are to become indicators that would enable to describe the behavior of the analyzed field [172]. However, to perform this type of analysis one must consider that full access to scientific production is unattainable [17], reason for which reliable and rigorous sources must be regarded to ensure the relevance and significance of the knowledge to which one has access, being the choice of the database from which the information will be obtained, the fundamental starting point to begin this process [138].

It is important to highlight that similar studies in the same area of interest have been conducted; for example, the one carried out by [83], which explored worldwide tendencies of e-commerce during the 1996-2012 period. Some important results from this study evidenced working papers, and articles as the main type of documents in which the matter was reported. Besides that, the three main conferences on the topic analyzed reached a participation of the $10,6 \%$ of the total of working papers and the first 20 publications participated with a $31,1 \%$ of the total of journal articles. Finally, Computer Science Information Systems, Business, and Informatics Theory Methods were the three most popular topic categories found.

In a similar study conducted by [124], a bibliometric analysis of online shopping was carried out. This analysis was done in the Web of Science (WOS) data base during the period 2000-2014, generating 772 related articles, which were analyzed under the criteria of productivity, sustainability, and impact. Within their main conclusions, the authors state that online shopping is becoming increasingly popular worldwide and highlight Journal of Business Research, Marketing Science, Information and Management, and Psychology and Marketing as the top journals publishing articles under the three evaluation criteria used to carry out the analysis. However, as there is no single prominent journal on the subject studied, research publications on the matter are fragmented, and researchers publish their work on a variety of journals in the fields of technology, marketing, operations, or management, depending on the content of the paper and the authors' preference. Finally, the authors point out Izak Benbasat as the top author of papers written from the perspectives of productivity and sustainability, since he wrote 10 articles in 7 different years within the period studied.

Bibliometric analysis has thus been proven a methodology that permits a quantitative identification of tendencies and behavior on a specific area of study through a variety of indicators, depending on the factors of interest identified for a particular research study [198]. The bibliometric approach is mainly based on the search of quantitative characteristics of the topic studied: features of research publications, such as article titles, key words and phrases; authors, including their institutional afiliation, coauthors and reputation; and books and journals, including titles, topics and country of origin [75], permitting the identification of patterns useful for research advance and scientific development [148]. In this article, a bibliometric analysis of the factors involved in the adoption of e-commerce was made from the data of academic publications reported by the SCOPUS database. SCOPUS provides tools to manage information, and meets other criteria such as the amount of citations and accessibility, which make it one of the most used databases in this type of analysis in the literature [77]. Besides its accessibility, SCOPUS was selected in this study due to being considered a valid, reliable, and timely source of academic information, which makes it the largest database regarding citations and abstracts from peer-reviewed literature and highquality sources in the Web [83], [124]. On the other hand, the researchers intended to address a data base different from the one used in the studies mentioned (WOS). In addition, high levels of correlation in their reported bibliometric indicators have been found between Scopus and WOS, which make the two data bases statistically comparable and stable. Thus, the indicators of production and scientific quality would equally support findings generated by either of the two data bases [16].

Subsequently, a search equation was defined per the object of bibliometric analysis; i.e., the factors involved in the adoption of e-commerce. For this purpose, key terms equivalent to electronic commerce (e-commerce - electronic commerce) were considered as search criteria along with stems equivalent to the term adoption (appropriat * - adopt *). Those key terms were searched in the title and keyword fields, with no restriction of time for a broader horizon of analysis (taking as cutoff date, items recorded in Scopus until April 1, 2017). Tests with 7 equation options, which 
differred from each other in their key words, distance between the terms, and the search scope (between title, abstract, key words and full text), were carried out. The analysis of results and consensus among the participating researchers determined the following search equation: TITLE (e commerce W/5 adopt ${ }^{*}$ ) OR (e commerce W/5 appropriat* ) OR KEY ( electronic W/5 commerce W/5 adopt* ${ }^{*}$ OR ( electronic W/5 commerce W/5 appropriat*), which was the one that reported the highest affinity with the studies conducted on the theme. Including and excluding criteria were completely based on the search equation since all the downloaded articles resulting from the search were analyzed. The equation yielded a total of 408 records, which were processed and interpreted using Microsoft Excel and Data Analyzer (Thomson Reuter's software) to identify indicators of quantity and quality. In addition, free software CYTOSCPE was used for calculating indicators of structure and network topology maps of authors.

Among the indicators calculated in this study, there were statistics about activity (amount) that permitted visualizing the state of the art, within which the number and distribution of publications, productivity, dispersion of publications, and collaboration in publications are included. Likewise, there were impact indicators (quality), used to assess the incidence of authors, papers, and / or journals in a specific area or discipline [28], [53]. Finally, there were structure indicators that allowed measuring connections between different authors and publications [170].

Some of the indicators permitted to evidence the factors involved in the adoption of e-commerce in terms of quantity, indicating items with higher impact such as the years with the highest production, the most representative journals, and the most prolific authors in the area. The measurement of publication quality through impact (in terms of number of citations) is widely accepted, mainly based on what the Frascati Manual and the Organisation for Economic Cooperation and Development (OECD) propose for the measurement of Research and Development (R\&D) activities, and the analysis of research systems and scientific specialization both of researchers and countries [53], [95], [130], [140], [163]. Based on the previously mentioned, the number of citations of an article has been taken as a point of reference for the calculation of quality indicators. By the same token, quality indicators facilitated to explain authors' impact, and reasons for journals and articles to be the most outstanding and cited [95], [140], [163]. Structure indicators allowed to observe the behavior of working nets on the theme [70], [210]. Finally, trends in the study of the explored field were analyzed through the observation of the behavior of the key words, which permitted identifying increasing, decreasing and emergent fields in the area [198].

\section{Findings}

The results of the analysis are presented in this section based on the indicators proposed in the methodology. The information has accordingly been grouped in four categories: quantity indicators, quality indicators, indicators of structure, and research trends in e-commerce adoption factors.

\subsection{Quantity Indicators}

Based on the obtained search equation, the bibliometric quantity indicators calculated for the topic of Electronic Commerce are laid out in this subsection of the findings.

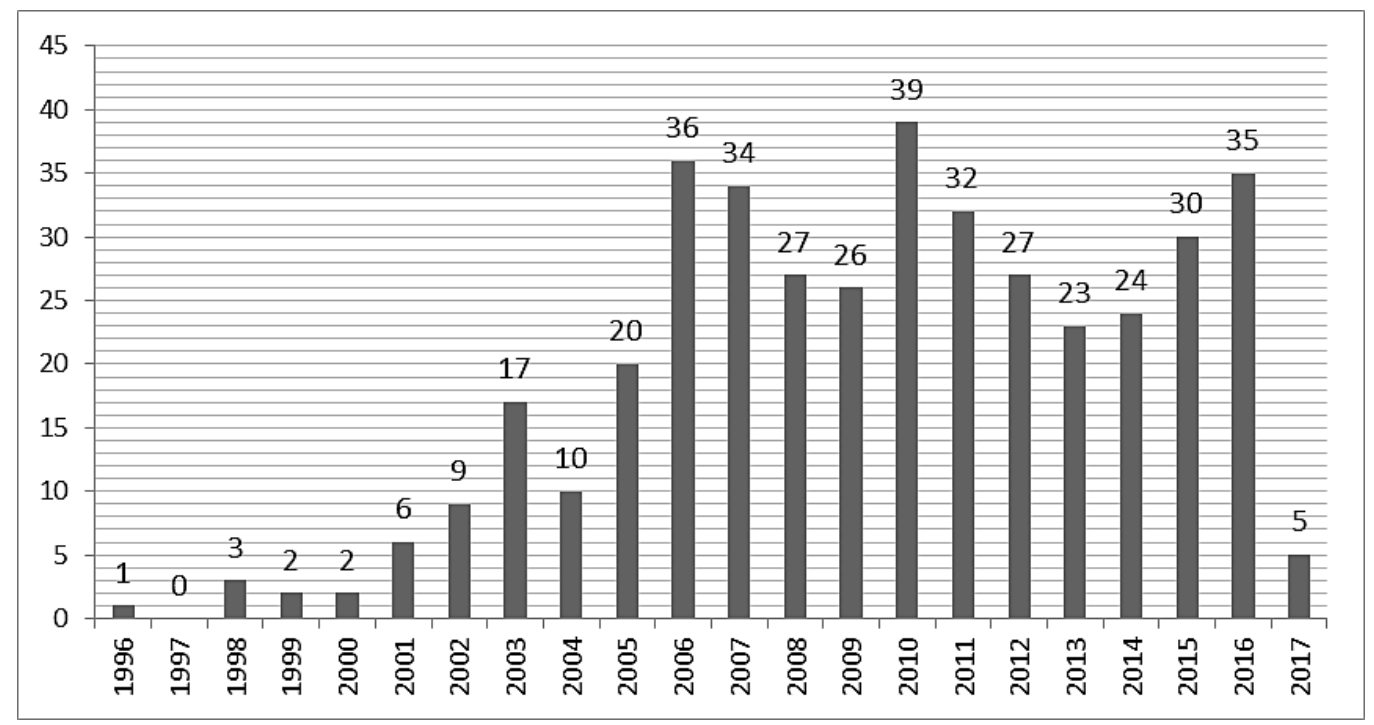

Figure 1: Number of publications by year Source: compiled from bibliometric analysis

In Figure 1, the indicators show a growing interest on the topic since 2001, 2006 being one of the most productive years with a number of 36 published articles. In the following years of 2007 to 2009, the number of publications 
decreases steadily to present a new increase in 2010, this being the year of the highest increment with 39 published articles. From 2011 to 2016, a steady decline in the number of publications has been showing, which may be an indication that the identification of factors of adoption of e-commerce had its process boom between 2001 and 2006 in the theoretical realm and retaking known models of technology acceptance. Later, we have seen that publications have focused more on identifying adaptations of adoption models according to the particular socio-cultural, economic and demographic contexts. In conclusion, we observe that research tendency in the topic has focused on more specific alternatives, opting for the evaluation of factors in particular business dynamics (small and medium-sized business). Such evaluation has been based on the use of quantitative models in agreement with the Diffusion of Innovation Theory, in which inquiry about the validity of the factors of those models and their pertinence in the successful adoption of ecommerce has been conducted.

To determine the journals with major impact in the field, it is necessary to identify the ones that publish the $80 \%$ of research studies on the topic [117]. However, regarding the topic of this article, that percentage is disseminated among $62.07 \%$ of the journals (87 journals) that publish on the subject; therefore, it is not possible to present a traditional graphic grouping the journals with the highest production. It was thus considered appropriate to take the 10 main journals that publish on the topic as a reference, selected on the basis of the number of articles that address ecommerce adoption factors (the number of citations from these studies has not been considered yet). Accordingly, Figure 2 presents the ten journals with the largest number of publications related to the field of study.

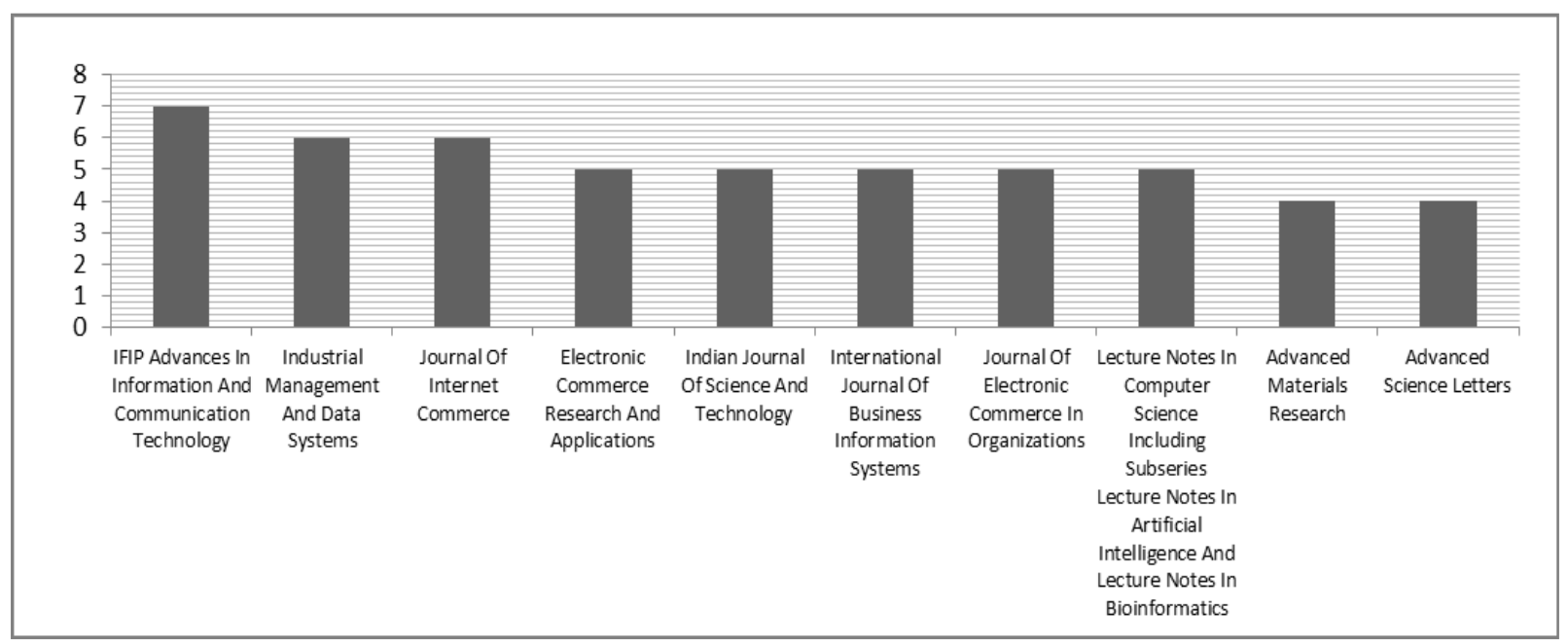

Figure 2: Number of publications by journal Source: Compiled from bibliometric analysis

IFIP Advances in Information and Communication Technology, is the top journal with 7 articles published. This publication compiles the disclosures made in the framework of the International Conference on Electronic Business (ICEB), where technology issues involving e-commerce are discussed, ranging from platforms and Web services, to knowledge models for e-commerce for both the environment and the company, as well as peculiarities of the different applications of this technology [118]. The second journal, with 6 articles, is the Industrial Management and Data Systems, in which papers about the social, cultural, organizational and cognitive impacts of e-commerce technology and advances in organizations worldwide are published [120]. The third journal with most publication is the Journal of Internet Commerce, with 6 articles, which "promotes greater access to high quality presentations at conferences and workshops on computer fields" [121]. The fourth publication, is the Electronic Commerce Research and Applications Journal [57], [122] with 5 articles. This journal aims to create and disseminate knowledge about e-commerce, considering it is a multidisciplinary area that should be developed in cooperation with other existing fields, such as Information Systems and Technology; Marketing, Finance and/or Supply Chain Management; Strategy and Management; Public policy; Telecommunications and Computer Science; and Legal Studies. In fifth place is the Indian Journal of Science and Technology with 5 articles and the following four publications have 4 articles each: Advanced Materials Research; Advanced Science Letters; Journal of Small Business and Enterprise Development; and finally, Mediterranean Journal of Social Sciences.

To continue the analysis of the cumulative percentage of publications per journal, Figure 3 permits to conclude that there is no Pareto Law, due to $62.07 \%$ of the journals published $80 \%$ of the items. Therefore, we proceeded to separate the percentage of journals per quartile, obtaining the following results: (1) $9.20 \%$ of the journals published $25 \%$ of the articles; (2) showing a significant increase in the proportion, $24.14 \%$ of the journals published $50 \%$ of the articles; and (3) the remaining $52.9 \%$ of the journals published $75 \%$ of the articles. This shows that on the subject of adoption factors of e-commerce, knowledge is dispersed among several journals related to the area of Information Technology and Communication, and there are no publications with a significant concentration of studies on the field. 


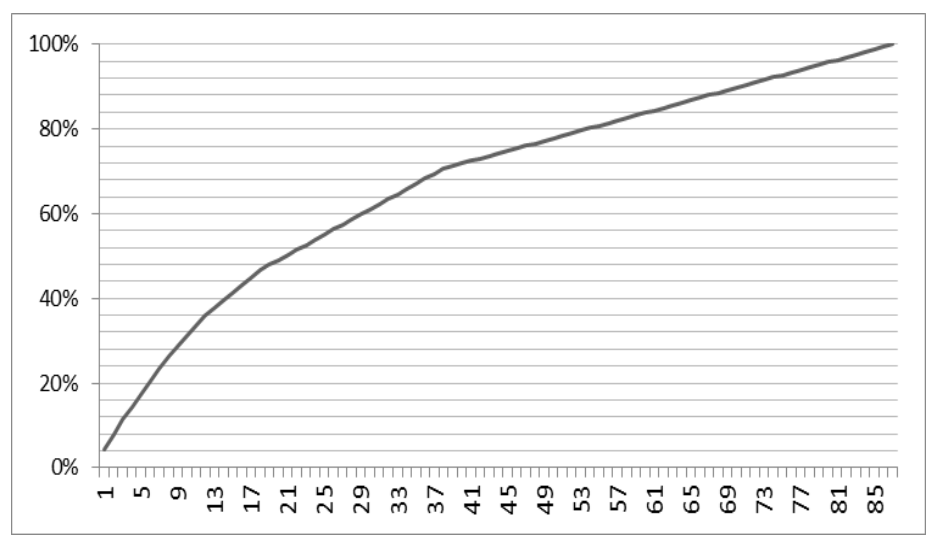

Figure 3: Cumulative percentage publications by journal Source: Compiled from bibliometric analysis

Regarding the analysis of researchers with production in the field, Figure 4 displays the list of the ten researchers who have most productions in this subject area. MacGregor, R.C., who has 9 publications, appears on the top. Robert MacGregor is an associate professor in the School of Informatics and Computer Science at the University of Wollongong in Australia. His research expertise is in the area of information technology (IT) and electronic commerce (E-commerce) in small and medium sized enterprises (SMEs). He is the author of articles and conference publications examining the use and adoption of ICT in SMEs series. MacGregor is also the founding editor of the Australasian Journal of Information Systems and was president of the Australian Information Systems Conference in 1992 [124]. The following authors in the list are Vrazalic, L., with 8 publications; Govindaraju, R., Kartiwi, M. and Zhu, L., with 5 publications each; Kurnia, S., Scupola, A. and Thatcher, S.M.B., with 4 articles each; and the last two authors with 3 publications each are Al-Somali, S.A. and Chandra, D.R. (Figure 4).

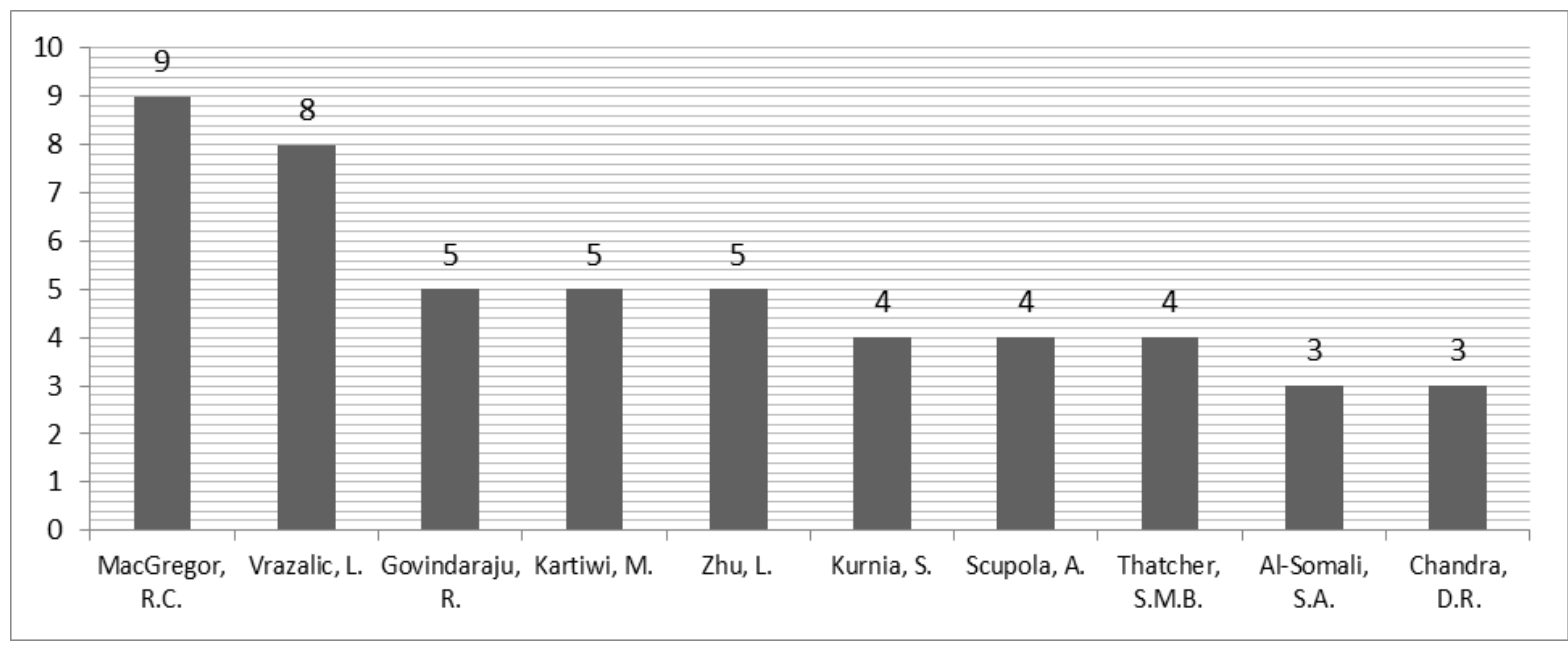

Figure 4: Authors with higher production Source: Compiled from bibliometric analysis

In connection with the number of publications by journal, the cumulative amount of publications of the top ten authors (see Figure 5) shows that there is no Pareto Law, since $63.46 \%$ of the authors published $80 \%$ of the articles. Given this situation, we proceeded to separate the cumulative percentage of publications for the first ten authors, by degree of relevance, obtaining that: (1) $12.18 \%$ of the authors published $25 \%$ of the articles; (2) $34.62 \%$ of the authors published $50 \%$ of the articles; and (3) $59.0 \%$ of the authors published $75 \%$ of all articles. The information collected reveals an equitable distribution of articles per researcher; i.e., in terms of number of publications no author stands out. 


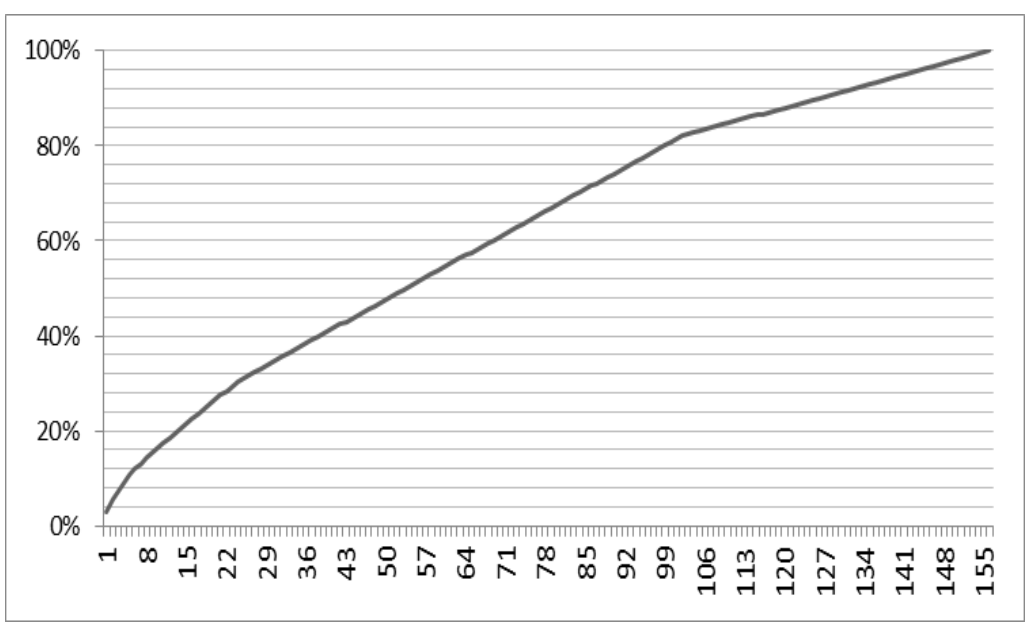

Figure 5: Cumulative percentage of publications by author Source: Compiled from bibliometric analysis

By applying natural logarithm to each of the axes, the law of productivity was obtained for journals (Figure 6) and for authors (Figure 7). This law postulates that productivity does not follow a linear but logarithmic distribution; it can thus be inferred that "the more published articles an author has, the easier it seems for them to produce and publish" [124]. In conducting this analysis, the authors of a given set of publications are distributed in three levels of productivity: the small producers $(\log n=0)$, the media producers $(1>\log n>0)$ and the large producers $(\log n>1)$ [125]. Figure 7 shows the squared value of the regression coefficient of the adjustment on cumulative number of articles against the natural logarithm of journals, being greater than 0.9 , demonstrating a proper fit for the proposed model for productivity.

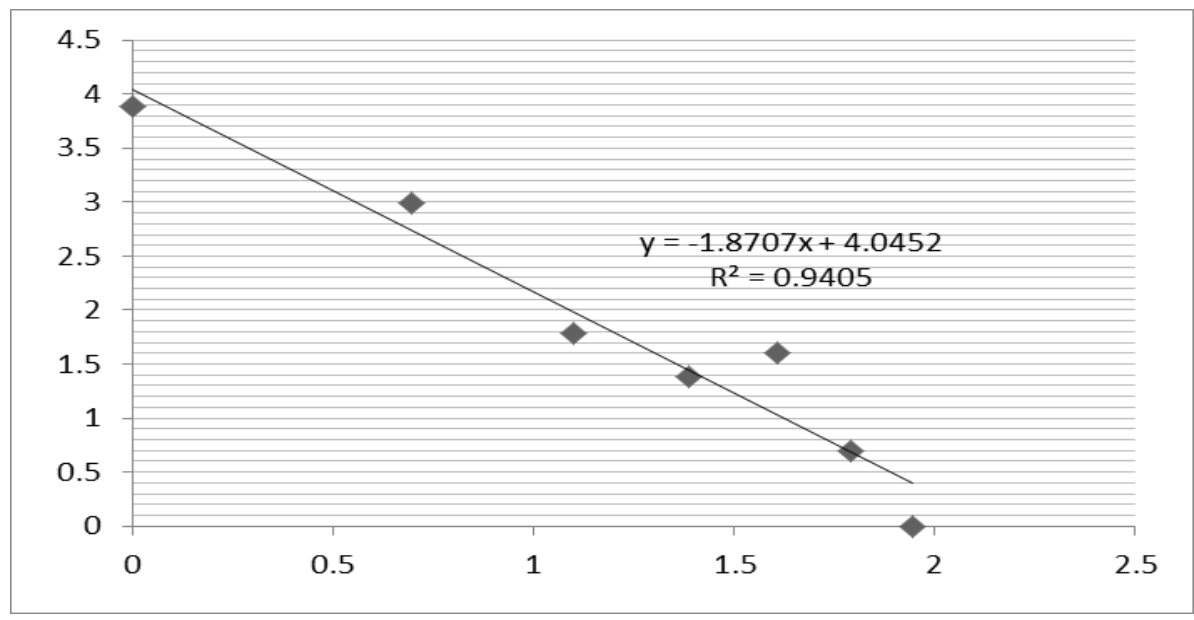

Figure 6: Productivity law by journals Source: Compiled from bibliometric analysis

The law of productivity was also verified for authors in the field. Figure 7 presents the results obtained with respect to this law. The graphic shows a determination coefficient greater than 0.8 confirming a suitable adjustment for the proposed model for productivity. As mentioned above, the authors analyzed have an average level of productivity. 


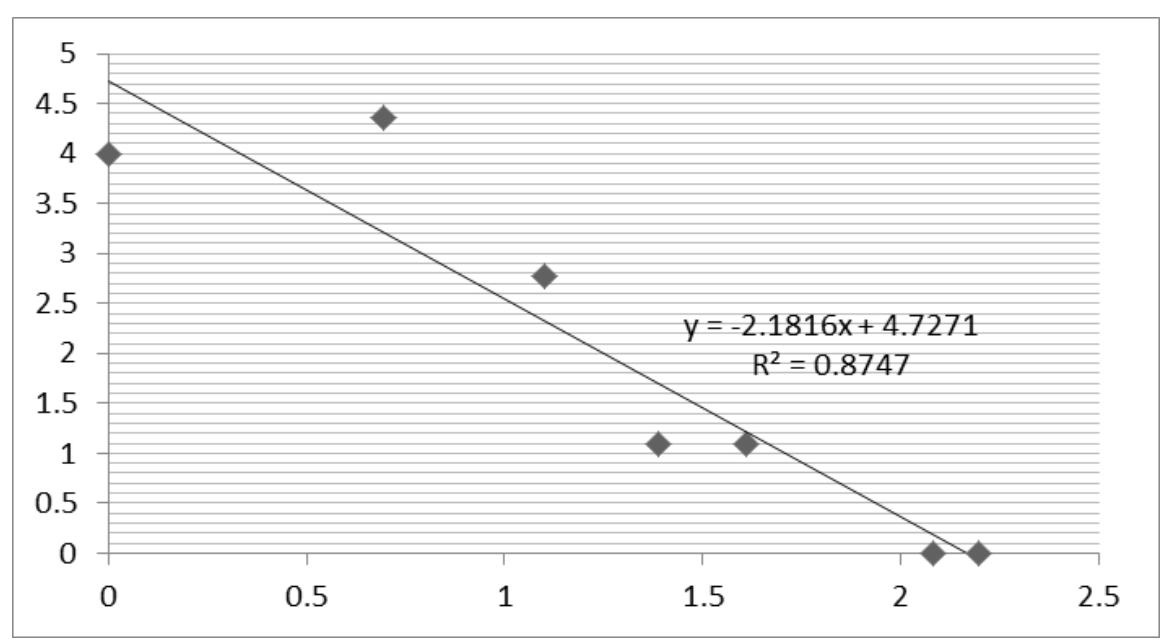

Figure 7: Productivity law by author

Source: Compiled from bibliometric analysis

Finally, it is worth noting that $48 \%$ of the records obtained from the search equation correspond to articles and $40 \%$ are papers presented at conferences. The participation of other types of documents on Electronic Commerce is $7 \%$ (see Figure 8). Accordingly, one could say that the dissemination of academic and research findings in this field is mainly concentrated on publications in refereed journals and participation in conferences that allow greater interaction and associativity between authors.

In addition, classifying these publications by area of knowledge shows that most of them are located in the area of Computer Science (50.0\%) followed by the area of Business, Management and Accounting (38.9\%), Engineering (18.1\%), Social Science (15.9\%), and Decision Science (13.4\%). This shows that the main interest has focused on developing better computer systems (software, apps, etc.) that allow greater acceptance of e-commerce in contrast to the area of Business and Management, which pursues a greater ownership of technology towards improving profitability levels and the use of such means for companies to sell their products and for consumers to make their purchases.

\subsection{Quality Indicators}

This section presents the bibliometric indicators for quality, calculated for the factors of adoption of e-commerce, according to the defined search equation. As mentioned above, quality indicators are closely related to the publication impact; in other words, the number of its citations, [53], [69], [95], [130], [140], [163], [198], [210].

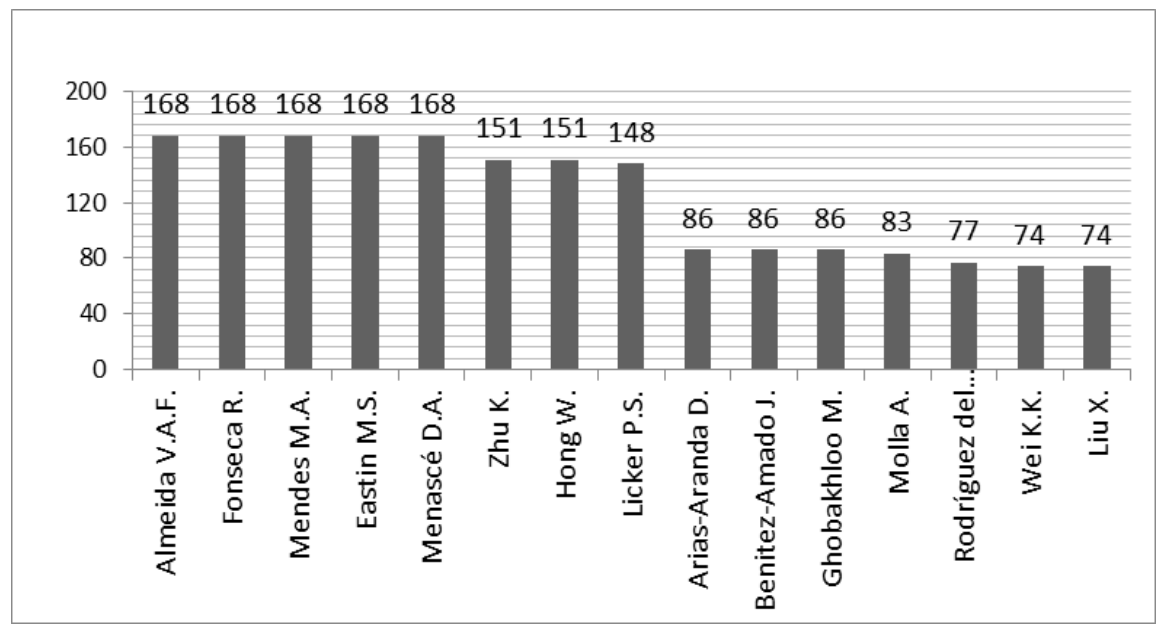

Figure 8: Number of citations by author Source: Compiled from bibliometric analysis

Based on quality indicators, it was possible to find the ten authors with most citations on the subject (see Figure 8). Within those ten are Almeida V.A.F. et al., who tops the list with 168 citations. Their publication dates to 1999, and it is an investigation that proposes a methodology for characterizing and generating e-commerce workload models. In the paper, the authors first introduce a state transition graph called Customer Behavior Model Graph (CBMG), used to describe the behavior of groups of customers who exhibit similar navigational patterns. Following, a set of useful 
metrics, analytically derived from the analysis of the CBMG is presented. Next, they define a workload model and show the steps required to obtain its parameters. Finally, they propose a clustering algorithm to characterize workloads of e-commerce sites in terms of CBMGs [125], [128]

The consecutive authors in the graph with the highest number of citations are the researchers Kevin Zhu and Weiyin Hong, who have 151 citations each, of an article whose methodology was based on multi-nominal logistic regression, demonstrating that technology integration, web functionalities, web spending, and partner usage were significant adoption predictors. The model showed that these variables could successfully differentiate non-adopters from adopters. Further, the migration model demonstrated that web functionalities, web spending, and integration of externally oriented inter-organizational systems tend to be the most influential drivers in firms' migration toward ecommerce, while firm size, partner usage, electronic data interchange usage, and perceived obstacles were found to negatively affect e-commerce migration [82], [126]. This study provided adequate tools for the implementation of strategies that would adopt Internet services in a cultural environment different from that of developed economies.

The following researcher within the top ten in the list is Licker P.S., with 148 citations recorded. This article from 2005 shows that the effects of network externalities influence the based on perceived organizational e-readiness (POER) and perceived environmental e-readiness (PEER) [127], [134]. The quality indicator does not have any similarities with that of quantity, because none of the 10 authors with the highest number of citations is part of the 10 authors with the highest number of publications (compare Figures 4 and 8 ).

Regarding impact, the journal with the highest number of citations is International Journal of Electronic Commerce (IJEC) [90], with 148 citations. The IJEC is a quarterly journal devoted exclusively to electronic commerce, which aims to provide an integrated view of the field by presenting approaches to multiple disciplines. It does so through the publication of topics such as the effects of e-commerce market, the transformation of the organization with e-commerce, business models in e-business, management and supply chain collaborative commerce, the co-creation in ecommerce, social network analysis, and e-commerce in the globalization of business, among others [136]

Information and Management, with 78 citations, stays in second place. This journal serves managers, professionals, database administrators, and senior executives of organizations, which design, implement and manage Information Systems Applications. The major aims of the journal are (1) to collect and disseminate information on new and advanced developments in the field of applied information systems; (2) to provide material for training and education in administrative data systems; (3) to encourage further progress in information systems methodology and applications; and (4) to cover the range of information system development and usage in their use of managerial policies, strategies, and activities, for business, public administration, and international organizations [135].

Below in the list is the European Journal of Purchasing and Supply Management with 72 citations. This journal fulfilled its 30th anniversary making contribution to research. It provides integrated information systems and how these can be developed and used effectively, to manage information and knowledge that may lead to more effective results in the organizations' vision [137].

Out of the 20 journals with the highest number of citations in the topic, $62.50 \%$ pertain to Scopus Q1, 16.67\% to Q2, $8.33 \%$ to Q3, and about $12.50 \%$ are not ranked in the quartile due to being Proceedings (see figure 9). This fact evidences that the journals with the highest quality are the ones that report a higher number of citations in the topic. Besides that, among the thematic areas published in these journals, two approaches stand out: (1) a Business Management approach, with the following subtopics declared in Scopus: Business and International Management, Management of Technology and Innovation, Strategy and Management; and (2) a Systems Approach with the following subtopics declared in Scopus: Computer Networks and Communications, Information Systems and Management, Human-Computer Interaction, and Information Systems, which evidences the interest in both fields of knowledge about publications related to e-commerce adoption factors. Finally, the bibliometric analysis identified that the topic of Electronic Commerce has been studied since its inception in 1996, when 3 citations were recorded. In the years 1998 and 1999, the thematic one obtained a significant increase in the number of citations, with 47 in 1998 to reach the highest number of citations, 104, in 1999. The article that achieved this amount of citations is the aforementioned Methodology for Workload Characterization of E-commerce Sites showing that the most outstanding authors of the thematic have contributed the findings with greatest value in the field [125] (see figure 10). 


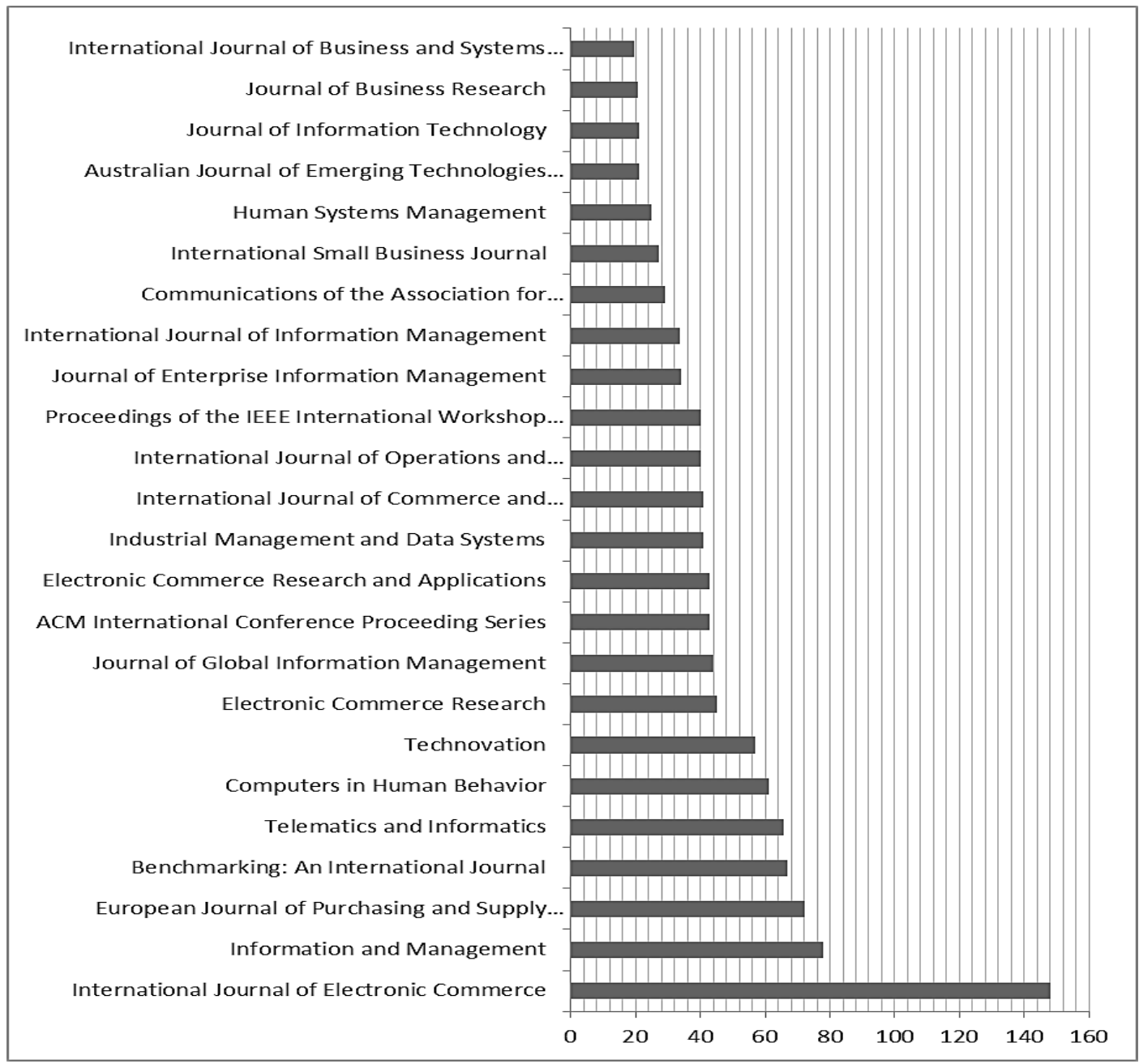

Figure 9: Number of citations by journal Source: Compiled from bibliometric analysis

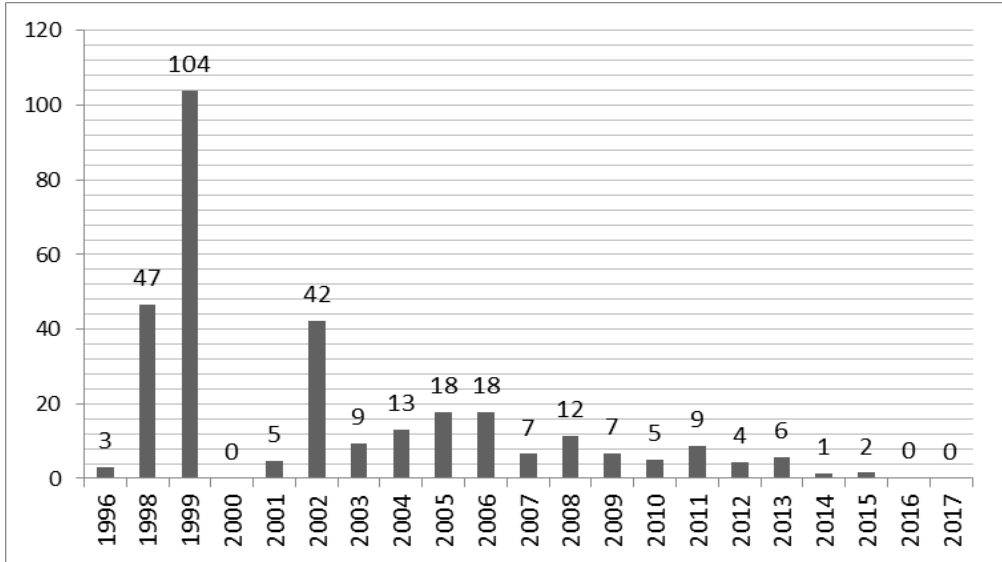

Figure 10: Number of citations by year Source: Compiled from bibliometric analysis

\subsection{Indicators of Structure}

Structure indicators measure the connectivity between publications [138], the authors, and areas of knowledge; these are often associated with the construction and analysis of social networks, which consist of nodes (vertices) and links. In the case of a bibliometric analysis, nodes are authors (people who research and publish their results) and links represent co-authorships. Thus, from the analysis of these ${ }_{51}$ networks, it is possible to identify outstanding 
researchers in the field and define the dynamics with which they work together [139]. The results of the indicators of the network of authors are presented in Table 3.

Table 3: Structure indicators

\begin{tabular}{|l|l|l|}
\hline Indicator & $\mathbf{1 9 9 6 - 2 0 0 5}$ & $\mathbf{1 9 9 6 - 2 0 1 7}$ \\
\hline Number of Nodes & 148 & 863 \\
\hline Network Density & 0,013 & 0,002 \\
\hline Network Diameter & 2 & 4 \\
\hline Expected Characteristic Distance & 1,028 & 1,210 \\
\hline Number of connected components & 64 & 327 \\
\hline Number average neighbors & 1,851 & 2,125 \\
\hline Degree of network clustering (Clustering) & 0,577 & 0,622 \\
\hline Network Centralization & 0,022 & 0,010 \\
\hline Network Heterogeneity & 0,657 & 0,671 \\
\hline Number of isolated nodes & 18 & 69 \\
\hline Node connected Components & $43,24 \%$ & $37,89 \%$ \\
\hline Nodes Isolated Components & $12,16 \%$ & $7,99 \%$ \\
\hline
\end{tabular}

Source: Own elaboration, done with cytoscape software

The analysis of structure indicators arose 863 authors in the field, and evidence that, on average, each author has published with 2 other authors $(2,125)$. Additionally, the network density was found to be close to zero $(0.002)$, which shows that the strength of connections between the authors of the entire network is very low. This could indicate that the dispersion of production is significant. In addition, the group subnets formed between its nodes (authors) is also significant since they have a degree of clustering of 0.622 . This does not however imply connectivity since heterogeneity $(0.671)$ was found to be greater than said grouping--which implies that some subnets tend to look like a star. This shape means that there is a central node in the subnet connected to the others, which can be a bridge for connections between authors while their disappearance could cause the isolation of nodes with which it has links; i.e., an author is the one who serves as a connection with others to work the different subject area knowledge.

The typical explanation about cohesion for the effect of network position on knowledge outcomes is that centrality provides individuals with timelier access to richer and more diverse information, increasing the extent to which they learn from their network and their potential to synthesize and recombine this information into novel ideas [153]. At the other extreme of the spectrum, the cohesion perspective views ties as pipes through which information and knowledge flow and characterizes network position in terms of centrality; that is to say, the extent to which an individual is well connected, both directly and indirectly, to others in the network.

Networks are not merely a representational form of social relations. Instead, research in network theory posits that the structure of relationships affects the opportunities and constraints of individual action and their outcomes. Networks affect opportunities for action [68]; additionally, the collective actors as well as the relations that they sustain are the building blocks of social networks.

Table 1 also shows the cumulative structure indicators in two periods (1996-2005 and 1996-2017), with the purpose of analyzing the evolution of the network of authors over time. There, there is an increase in the number of authors (number of nodes), number of independent authors (number of isolated nodes), and number of isolated subnets (number of isolated components). However, the growth rate of the nodes is much larger than that of the isolated nodes and connected components. Therefore, there is a decrease in the dispersion of isolated subnets and independent publications (variations of component indicators connected by nodes and components isolated by nodes respectively). Evidently, authors who are adhering to the field, do so by means of already formed networks.

In this sense, the subnets have been increasing in size and decreasing in density, which is reflected in the evolution of the degree of clustering and the diameter of the network. In spite of this, a slight increase of the density of the network reflects that the new authors are related to some few authors of the subnet to which they were connected, and as a consequence the expected characteristic distance has not undergone variations.

Another characteristic evidenced in this network of authors is that there is only one link of the shortest path that connects all the nodes of a network $(1,210)$ and that in turn, the maximum distance between any pair of nodes of the network is equivalent to 4 , which corresponds to a typology of networks of internal knowledge management, used to maximize the application of individual knowledge to the objectives of the organization. These networks evolve through thematic mapping of experience within the organization, and environments conducive to knowledge sharing [143]. 
On the other hand, the network is increasingly decentralized and more heterogeneous; that is, there are no common central authors for the entire field, but there are no common central authors for the subnetworks. There is a possibility that these subnetworks are related to the disaggregation of the field of knowledge and therefore may represent the fragmentation of knowledge. Finally, the study examined search conceptualize knowledge networks as consisting of nodes that serve as repositories of knowledge and agents that search for, adopt, transmit, and create knowledge. For this reason, nodes are simultaneously sources and recipients of information and knowledge. Likewise, such relationships constitute a means by which nodes search for information and knowledge; a medium through which information and knowledge diffuse and flow.

\subsection{Research Trends in E-Commerce Adoption Factors}

Keyword analysis is used to identify the topics studied in the field that are generating greater publication, i.e. have a greater research tendency. Figure 11, presents the keyword dynamics, which is constructed by performing a normalization of keyword search criterion, linking concepts with the same meaning, and making a thesaurus of keywords recovered in the search. Afterwards, a count of the words is performed in order to spot the most important ones. This analysis is important because they are the words used by the authors to characterize their investigations, which turns them into a source of primary information.

In Figure 11, the most dynamic topics in the analyzed period are evident. Accordingly, SMEs becomes the keyword that has the highest recurrence and therefore the context in which e-commerce is being researched the most. Such research shows that e-commerce is being implemented in the SMEs, through the use of information and communications technologies (ICT) to facilitate its access [21], [98], [110], [120], [125], [126], [147]. In this regard, it is clear that promoting e-commerce in the sectors of small and medium sized enterprises has become a national development policy in some countries [40]. Similarly, in Latin America, there have been studies that have identified factors that reflect greater impact on the adoption of electronic commerce, namely the company size and their level of maturity in the implementation of ICT [54]. On the other hand, [112] discusses the importance of the use of e-commerce for the development of small and medium sized enterprises as it constitutes a source of competitive advantage. Other studies examine the effectiveness and impact of government policies to support the use of e-commerce and propose some recommendations [106]. The study of [159] concludes that the rate of adoption of e-commerce in SMEs is directly related to the rate of adoption of ICT. Meanwhile, [147] presents evidence that SMEs are more prone to the adoption of electronic commerce, and have more financial and technological resources as well as greater external pressure to be part of such trade.

The second recurrent keyword in Figure 11 is adoption, which evidently refers to the adoption of e-commerce. It indicates that research has explored the effort that is being made in small and medium-sized companies in emerging countries to incorporate e-commerce to improve performance [94], [116], [120], [123], [125], [147]. Among the analyzed research, various factors of adoption of e-commerce are mentioned, and those that have to do with organizational and financial issues stand [4], [7], [26], [27], [72], [141], [196]; for example, [81] states that the Organization for Information Ecology (OIE) is an important factor for the adoption of e-commerce and the paper proposes a model that integrates this vision to previously known factors.

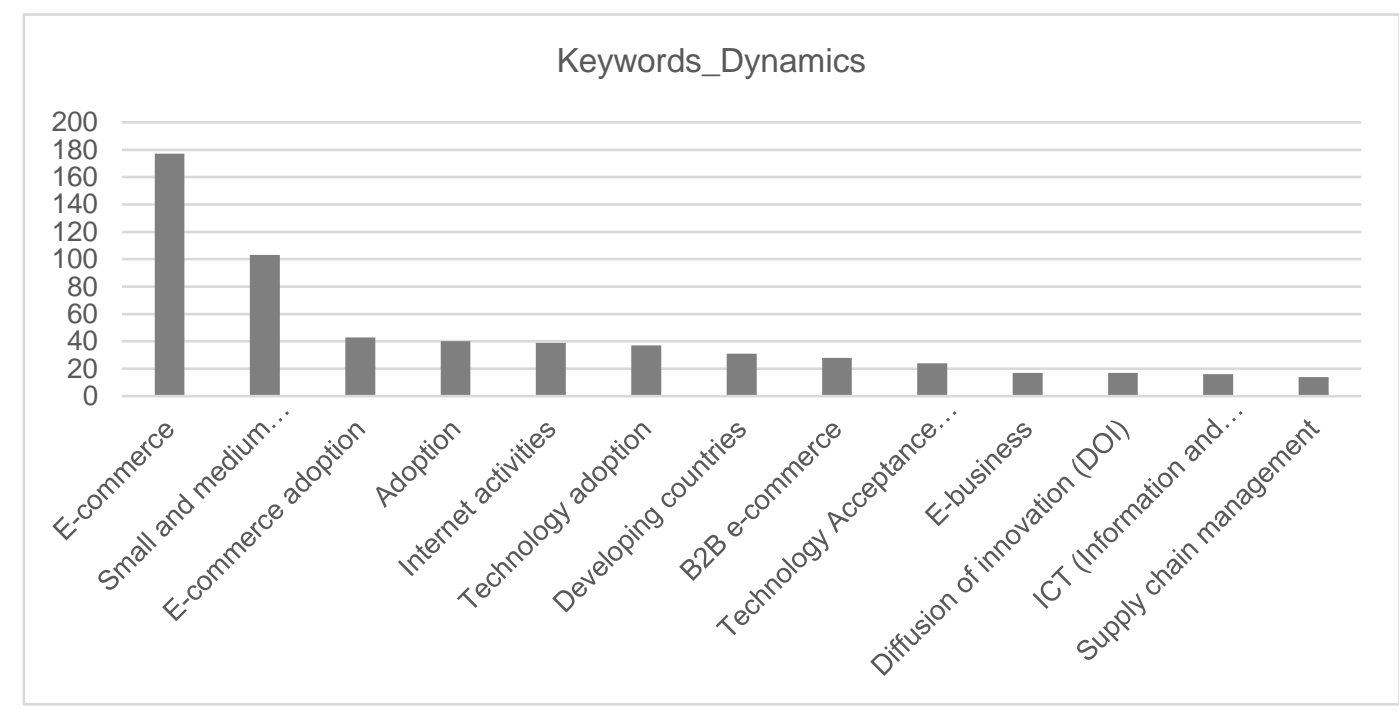

Figure 11: Keyword dynamics

Source: Compiled from bibliometric analysis

With respect to $B 2 B$ e-Commerce, studies show that foreign aid is crucial to increase the levels of its adoption, and that SMEs whose managers completed higher education are more likely to adopt it [112]. On the other hand, [125] examines, through the TOE Framework (Technology-Organization-Environment), the factors that allow the adoption 
of B2B e-commerce in Europe; as a result, the proposed model found seven factors including the development of technology, technology integration, the size of the company, the obstacles, the level of education, competitive pressures, and socio-business collaboration. The study also explained that the exponential growth of the Internet population encourages the adoption rate of e-commerce in different parts of the world. It is noteworthy that the adoption of B2B e-commerce in an emerging country was simulated with a model in which the size of the company, the business experience, the experience of Internet use, the amount of computer equipment, and the income and percentage gain of the company were considered as explanatory variables. This model showed that all variables except the business experience of the organization have a significant contribution to explain the adoption of electronic commerce by SMEs; in fact, it revealed that the number of employees and business experience of the company is negatively related to the adoption of electronic commerce [21].

With regards to Technology Acceptance Models, the Technology Acceptance Model (TAM) as well as the Theory of Diffusion of Innovation (IDT) and the TOE framework have been used in order to explain the adoption factors in small and medium sized enterprises in emerging countries [14], [19], [37], [64], [125], [176]. On the other hand, the study of e-business is specifically addressed by [184], showing the trends in research in this field; findings of this study also indicate that this field of research is multidisciplinary and is evolving to integrate with the supply chain as well as with specialized technologies in line [35]. The TOE framework identifies three contexts that can influence the use of a technological innovation in the field of organizational psychology [181]: technological context, organizational context, and environmental context [3], [84], [111], [113], [115], [191]. The TOE framework has been successfully used to understand the key factors of information systems that affect adoption [84].

Likewise, [47] introduced the Technology Acceptance Model to explain acceptance in the use of information technologies for the first time. This model is based on the Rational Action Theory (RAT), a psychological theory that intends to explain behavior based on intention. According to the RAT theory beliefs influence attitudes, which lead intentions, generating conduct [8]. The Technology Acceptance Model adopted this relation and applied it to the acceptance of information systems by users [1]. The TAM includes two primary predictors: the easiness of use and the perception of usefulness. Behavior intention acts as an independent variable, which in RAT is supposed to be tightly linked to actual behavior. This way, the TAM establishes the causal relations between perceived usefulness, perceived easiness of use, attitude towards use, and actual use of technology [105]. Finally, [145] argues that the TAM can explain user behavior through a broad spectrum of end user computing technologies.

Regarding the Supply Chain Management research has been conducted on its current and future state, focusing on the use of ICT, e-commerce and supply chains, and specifically on the type of technology being adopted, adoption factors, benefits, and barriers affecting the use of e-commerce as a way of innovation for logistics service providers [164]. In addition, [101], [162] conducted studies where B2B interactions were investigated in the supply chain showing that this tool improves its management. Finally, [25], [171] conclude that although the rate of e-commerce among providers of logistics services is small, those which have adopted e-commerce have seen a high level of benefits and a contribution to the development of e-commerce within the company in general terms.

Figure 12 displays the fields of research in e-commerce that are in growth, decrease, and increase; this analysis is based on the periodical behavior of keywords, allowing to identify trends for both the topics with a growing and less interest of researchers, and making evident the new topics of interest in the area studied. According to Figure 12, the research fields that are growing for the selected search are small and medium sized enterprises, adoption, developing countries, model of technology acceptance, e-business, information and communications technology (ICT), management of the supply chain, Theory of Diffusion of Innovations, ICT adoption models, and mobile commerce. These results point to the identification of e-commerce adoption factors in SMEs as an option to improve their position and competitiveness in the market. In addition, the graph pinpoints models that are being used to examine the factors that motivate the adoption of e-commerce such as Theory of Diffusion of Innovations and Technology Acceptance Models, and statistical analysis through Structural Equation Models. Regarding the fields in decline, the graph shows that these are electronic markets, consumer behavior, social theory, economic analysis, electronic data interchange, ICT adoption, optimization of mobile services, and tourism industry. Finally, the nascent fields are TechnologyOrganization-Environment framework (TOE) and adoption of systems.

Based on the identified themes, further research on the matter should focus in differentiating influencing factors in the adoption of e-commerce, based on the economical and social context of users, as in the case of variables such as private security and perceived risk, which usually differ according to the context. In addition, findings suggest researching about differences that can occur when population divisions such as gender, intention of using this channel for the shopping/buying of products, and the influence of culture in the adoption of e-commerce are made [97]. In the same vein, research studies should be linked to theoretical models of innovation adoption and diffusion, with the aim of having stronger statistical support in the analysis of variables. An approach based on the structuration theory, which focuses on studying social phenomena with the intention of understanding the interrelation between individuals and society [66] is one that could be useful in further research. On the other hand, theories of a stronger explanatory nature could be utilized to explain the role of culture in the generation of individuals' perception, which would lead to a better comprehension of the relationship between information privacy and culture [132]. Finally, one of the flaws in research in this field is the lack of studies with a longitudinal standpoint that could provide a better perspective in the process of adoption of electronic commerce from a followup of determined moments along the process. 


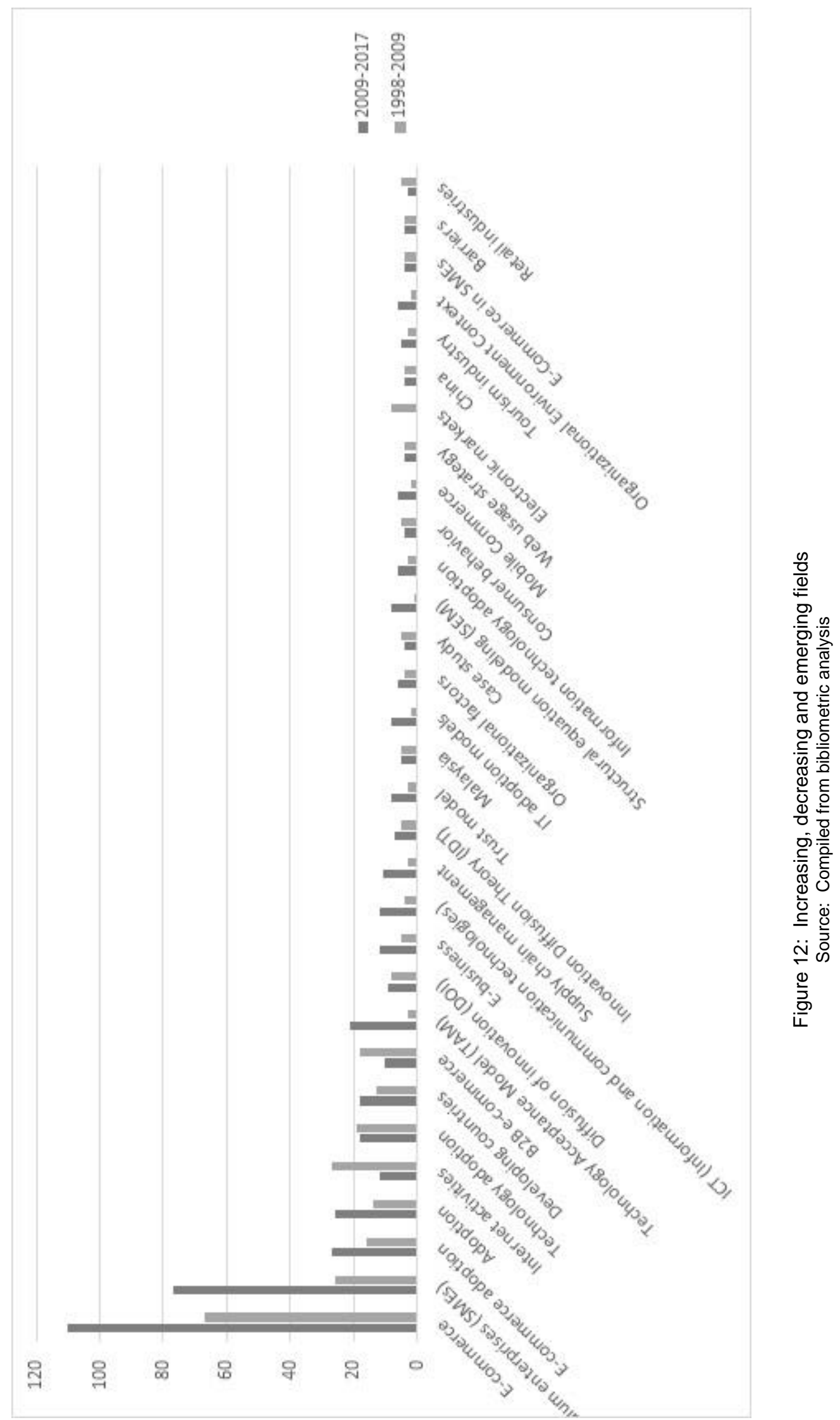


Based on the previous graphic, Table 4 groups adoption factors of electronic commerce through the analysis of the articles containing the key term adoption. The title of the article has been included to provide the focus and context of the article and facilitate constrast between the identified adoption factors. Following, we will provide an agenda intended to guide future research and provide recommendations about the important factors to be considered in the adoption of e-commerce:

Table 4: Adoption factors identified through paper with keyword adoption

\begin{tabular}{|c|c|c|c|}
\hline Authors & Title & Year & Adoption factors identified \\
\hline $\begin{array}{l}\text { Nickels and Kwun } \\
\text { [137]. }\end{array}$ & $\begin{array}{l}\text { The relationship between e- } \\
\text { commerce adoption and } \\
\text { organizational culture. }\end{array}$ & 2006 & $\begin{array}{l}\text { Organizational cultures with an emphasis on external } \\
\text { orientation and flexible structure, adhocracies, are typified } \\
\text { by leaders who are innovators and risk takers. This paper } \\
\text { proposes a research framework for exploring the } \\
\text { proposition that organizations exhibiting higher levels of an } \\
\text { adhocracy culture orientation will also exhibit higher levels } \\
\text { of e-commerce adoption. }\end{array}$ \\
\hline $\begin{array}{l}\text { Pearson and } \\
\text { Grandon [147]. }\end{array}$ & \begin{tabular}{|l|} 
An empirical study of factors \\
that influence E-commerce \\
adoption/non-adoption in small \\
and medium sized \\
businesses.
\end{tabular} & 2006 & $\begin{array}{l}\text { The results indicate that SMEs most receptive to adopting } \\
\text { e-commerce have the financial and technological } \\
\text { resources, see e-commerce as useful for their firms, and } \\
\text { feel external pressure to integrate e-commerce into their } \\
\text { organization. }\end{array}$ \\
\hline Reddick [162]. & $\begin{array}{l}\text { Government E-commerce } \\
\text { adoption: A study of Texas } \\
\text { counties. }\end{array}$ & 2006 & $\begin{array}{l}\text { For counties that had an e-commerce Website, improved } \\
\text { customer service was the most commonly cited impact. } \\
\text { The most frequently reported management barrier to e- } \\
\text { commerce adoption concerns problems with transaction or } \\
\text { convenience fees. Having an e-commerce Website was } \\
\text { associated with being a large county government. }\end{array}$ \\
\hline $\begin{array}{l}\text { Siyal, Chowdhry and } \\
\text { Rajput [180]. }\end{array}$ & $\begin{array}{l}\text { The adoption of E-commerce } \\
\text { by overseas Sindhis: An } \\
\text { empirical study. }\end{array}$ & 2006 & $\begin{array}{l}\text { The results indicate that income level education level and } \\
\text { exposure to the Internet were significant predictors in } \\
\text { explaining the rate of adoption of e-commerce by overseas } \\
\text { Sindhis }\end{array}$ \\
\hline $\begin{array}{l}\text { Tarafdar and Vaidya } \\
\text { [184]. }\end{array}$ & $\begin{array}{l}\text { Challenges in the adoption of } \\
\text { E-commerce technologies in } \\
\text { India: The role of } \\
\text { organizational factors. }\end{array}$ & 2006 & $\begin{array}{l}\text { The role of top management, aspects of organization } \\
\text { culture, characteristics of Information Systems } \\
\text { professionals, and organization structure. }\end{array}$ \\
\hline $\begin{array}{l}\text { Thatcher, Foster and } \\
\text { Zhu [188]. }\end{array}$ & $\begin{array}{l}\text { B2B e-commerce adoption } \\
\text { decisions in Taiwan: The } \\
\text { interaction of cultural and } \\
\text { other institutional factors. }\end{array}$ & 2006 & $\begin{array}{l}\text { Results indicate that organizational, industrial, } \\
\text { governmental, and cultural factors do indeed influence B2B } \\
\text { e-commerce adoption decisions. In addition, the nature of } \\
\text { the cultural influence is dictated by industry conditions. }\end{array}$ \\
\hline $\begin{array}{l}\text { MacGregor and } \\
\text { Vrazalic [118]. }\end{array}$ & \begin{tabular}{|l|} 
Strategic alliances and e- \\
commerce adoption in \\
regional SMEs: A comparative \\
study of Swedish and \\
Australian regional SMEs.
\end{tabular} & 2007 & $\begin{array}{l}\text { The results showed that membership in a strategic alliance } \\
\text { was associated with the rating of importance of e- } \\
\text { commerce adoption factors, but only for specific sections of } \\
\text { the SME population. The results also showed that these } \\
\text { associations are not universal, but differ from location to } \\
\text { location. }\end{array}$ \\
\hline $\begin{array}{l}\text { Qi and McGilligan } \\
\text { [159]. }\end{array}$ & $\begin{array}{l}\text { An investigation into E- } \\
\text { commerce adoption profile for } \\
\text { small and medium-sized } \\
\text { enterprises in Bury, greater } \\
\text { Manchester, UK. }\end{array}$ & 2007 & $\begin{array}{l}\text { Results show that the adoption rate of information and } \\
\text { communication technology (ICT) and e-commerce in Bury } \\
\text { is a step ahead of the UK in general. }\end{array}$ \\
\hline $\begin{array}{l}\text { Quaddus and Xu } \\
\text { [160]. }\end{array}$ & $\begin{array}{l}\text { Adoption of e-commerce: A } \\
\text { decision theoretic framework } \\
\text { and an illustrative application. }\end{array}$ & 2007 & $\begin{array}{l}\text { Extensive literature review that revealed a number of } \\
\text { factors or attributes that either act as drivers or barriers of } \\
\text { e-commerce success. }\end{array}$ \\
\hline $\begin{array}{l}\text { Sparling, Toleman } \\
\text { and Cater-Steel } \\
\text { [182]. }\end{array}$ & $\begin{array}{l}\text { SME Adoption of e-commerce } \\
\text { in the Central Okanagan } \\
\text { region of Canada. }\end{array}$ & 2007 & $\begin{array}{l}\text { The study found significant factors that differentiated } \\
\text { adopters and non-adopters of e-commerce included } \\
\text { technological opportunism and readiness, owner } \\
\text { experience with computers, support within the } \\
\text { organization, relative advantage and compatibility. }\end{array}$ \\
\hline $\begin{array}{l}\text { Wu, Zhang, Xing, Dai } \\
\text { and Du [202]. }\end{array}$ & $\begin{array}{l}\text { A study for understanding e- } \\
\text { commerce adoption in China's } \\
\text { service SMEs from web } \\
\text { usability perspective. }\end{array}$ & 2007 & $\begin{array}{l}\text { This paper supports that web usability is the core of e- } \\
\text { commerce adoption and states that understanding China's } \\
\text { service SMEs adopting e-commerce requires studying web } \\
\text { usability first. }\end{array}$ \\
\hline $\begin{array}{l}\text { Maswera, Dawson } \\
\text { and Edwards [127]. }\end{array}$ & $\begin{array}{l}\text { E-commerce adoption of travel } \\
\text { and tourism organisations in } \\
\text { South Africa, Kenya, } \\
\text { Zimbabwe and Uganda. }\end{array}$ & 2008 & $\begin{array}{l}\text { The African websites were found to be generally } \\
\text { informative but lacked interactive facilities for online } \\
\text { transactions. It is recommended that these African } \\
\text { organizations evolve their websites into marketing tools to } \\
\text { capitalize on the potential Internet market. }\end{array}$ \\
\hline $\begin{array}{l}\text { Peng and Kurnia } \\
\text { [149]. }\end{array}$ & $\begin{array}{l}\text { Exploring the national context } \\
\text { in Electronic Commerce } \\
\text { adoption in developing } \\
\text { countries. }\end{array}$ & 2008 & $\begin{array}{l}\text { This paper recognizes the unique national context of the } \\
\text { developing countries and argues that the national context } \\
\text { factors can have significant impact upon EC adoption by } \\
\text { organizations in developing countries. }\end{array}$ \\
\hline
\end{tabular}




\begin{tabular}{|c|c|c|c|}
\hline $\begin{array}{l}\text { Shah, Alam, Khatibi, } \\
\text { Ahmad and Ismail } \\
\text { [174]. }\end{array}$ & $\begin{array}{l}\text { Factors affecting e-commerce } \\
\text { adoption in the electronic } \\
\text { manufacturing companies in } \\
\text { Malaysia. }\end{array}$ & 2008 & $\begin{array}{l}\text { The multiple regression analysis results indicate that } \\
\text { relative advantage, compatibility, complexity, observability } \\
\text { and security appear significant. Relative advantage and } \\
\text { compatibility have positive and significant influence on EC } \\
\text { adoption whereas complexity and security have negative } \\
\text { effects. This study also revealed a non-significant } \\
\text { relationship between trialability and e-commerce adoption. }\end{array}$ \\
\hline $\begin{array}{l}\text { Elahi and } \\
\text { Hassanzadeh. [56]. }\end{array}$ & $\begin{array}{l}\text { A framework for evaluating } \\
\text { electronic commerce adoption } \\
\text { in Iranian companies. }\end{array}$ & 2009 & $\begin{array}{l}\text { The result indicates that there is a significant positive } \\
\text { relationship between degree of electronic commerce } \\
\text { adoption and stages of electronic commerce development } \\
\text { in the companies. }\end{array}$ \\
\hline Bao and Sun [22]. & $\begin{array}{l}\text { A conceptual model of factors } \\
\text { affecting e-commerce } \\
\text { adoption by SMEs in China. }\end{array}$ & 2010 & $\begin{array}{l}\text { A multi-level conceptual model of these aspects of factors } \\
\text { affecting e-commerce adoption in Chinese SMEs is } \\
\text { proposed on the basis of innovation diffusion theory, } \\
\text { technology acceptance model, institutional theory and } \\
\text { strategic orientation theory. }\end{array}$ \\
\hline $\begin{array}{l}\text { Hernández-García, } \\
\text { Iglesias-Pradas, } \\
\text { Chaparro-Peláez and } \\
\text { Pascual-Miguel [79]. }\end{array}$ & $\begin{array}{l}\text { Perceived compatibility and } \\
\text { the adoption of B2C E- } \\
\text { commerce by non-buyers. }\end{array}$ & 2010 & $\begin{array}{l}\text { The results have demonstrated the importance of } \\
\text { perceived compatibility as a significant factor to foster non- } \\
\text { buyers' adoption of electronic business-to-consumer e- } \\
\text { commerce (eB2C). }\end{array}$ \\
\hline Hwang [86]. & $\begin{array}{l}\text { An empirical investigation of } \\
\text { normative, affective, and } \\
\text { gender influence on e- } \\
\text { commerce systems adoption. }\end{array}$ & 2010 & $\begin{array}{l}\text { The moderating effects of gender are tested based on the } \\
\text { socio-linguistic literature. As expected, the influence of } \\
\text { social norms is stronger in the female group while the } \\
\text { influence of enjoyment is stronger in the male group. }\end{array}$ \\
\hline $\begin{array}{l}\text { Seyal and Rahim } \\
\text { [173]. }\end{array}$ & $\begin{array}{l}\text { Understanding electronic } \\
\text { commerce adoption in } \\
\text { bruneian SMEs: A replication } \\
\text { of the Application of TAM and } \\
\text { perceived strategic value } \\
\text { models. }\end{array}$ & 2010 & $\begin{array}{l}\text { Two out of three perceived strategic value factors are } \\
\text { significant, whereas four out of five adoption factors are a } \\
\text { significant determinant of e-commerce. }\end{array}$ \\
\hline $\begin{array}{l}\text { Abdulghader, Singh, } \\
\text { and Mohamed [2]. }\end{array}$ & \begin{tabular}{|l|} 
Impeding barriers for E- \\
commerce adoption in Libya.
\end{tabular} & 2011 & $\begin{array}{l}\text { Electronic commerce (e-commerce) has found its way into } \\
\text { many organizations globally, numerous studies reported } \\
\text { that its adoption have been constrained by inefficient } \\
\text { operation and lack of infrastructural facilities. }\end{array}$ \\
\hline $\begin{array}{l}\text { Govindaraju and } \\
\text { Chandra, [71]. }\end{array}$ & $\begin{array}{l}\text { E-commerce adoption by } \\
\text { Indonesian small, medium, } \\
\text { and micro enterprises } \\
\text { (SMMEs): Analysis of goals } \\
\text { and barriers. }\end{array}$ & 2011 & $\begin{array}{l}\text { This paper reports a study on goals and barriers of e- } \\
\text { commerce adoption by Indonesian SMMEs. Further, it is } \\
\text { found that human resources and source of information } \\
\text { factors are the most significant barriers for e-commerce } \\
\text { adoption by Indonesian SMMEs. }\end{array}$ \\
\hline $\begin{array}{l}\text { Chen and Holsapple } \\
\text { [35]. }\end{array}$ & $\begin{array}{l}\text { E-business adoption research: } \\
\text { Analysis and structure. }\end{array}$ & 2012 & $\begin{array}{l}\text { The study reveals that e-business adoption research is a } \\
\text { multidisciplinary issue. Particularly, e-business adoption in } \\
\text { organizations is moving toward an advanced stage in the } \\
\text { evolution continuum. }\end{array}$ \\
\hline $\begin{array}{l}\text { Van Huy, Rowe, } \\
\text { Truex and Huynh } \\
\text { [169]. }\end{array}$ & $\begin{array}{l}\text { An empirical study of } \\
\text { determinants of E-commerce } \\
\text { adoption in SMEs in Vietnam: } \\
\text { An Economy in Transition. }\end{array}$ & 2012 & $\begin{array}{l}\text { In this research, the authors adapt the Technology- } \\
\text { Organization-Environment (TOE) framework and test a } \\
\text { model of e-commerce adoption including numerous } \\
\text { internal and external factors identified in empirical studies. }\end{array}$ \\
\hline $\begin{array}{l}\text { Abou-Shouk, } \\
\text { Megicks and Lim [4]. }\end{array}$ & $\begin{array}{l}\text { Perceived Benefits and E- } \\
\text { commerce Adoption by SME } \\
\text { Travel Agents in Developing } \\
\text { Countries: Evidence from } \\
\text { Egypt. }\end{array}$ & 2013 & $\begin{array}{l}\text { This research aims to examine the perceived benefits of an } \\
\text { advanced level e-commerce adoption by Egyptian travel } \\
\text { agents. Results indicate that marketing and competition } \\
\text { benefits, essential benefits that support strategy and } \\
\text { development, and business efficiency benefits all positively } \\
\text { contribute to decisions that lead to an advanced level of e- } \\
\text { commerce being adopted. }\end{array}$ \\
\hline $\begin{array}{l}\text { Al-Somali, Gholami } \\
\text { and Clegg [12]. }\end{array}$ & $\begin{array}{l}\text { An investigation into the } \\
\text { adoption of electronic } \\
\text { commerce among Saudi } \\
\text { Arabian SMEs. }\end{array}$ & 2013 & $\begin{array}{l}\text { The authors find that the level of e-commerce } \\
\text { implementation has yet to mature and customer readiness } \\
\text { for Internet shopping must improve before e-commerce } \\
\text { reaches the levels of maturity seen in other regions of the } \\
\text { world. }\end{array}$ \\
\hline Bertea and Zait [24]. & $\begin{array}{l}\text { Perceived risk vs. intention to } \\
\text { adopt E. commerce - A pilot } \\
\text { study of potential moderators. }\end{array}$ & 2013 & $\begin{array}{l}\text { The purpose of this research was to investigate potential } \\
\text { moderator variables which could change the relationship } \\
\text { between perceived risk and the intention to buy online. } \\
\text { Although no moderation effect was proved, partly due to } \\
\text { the homogeneity of the investigated pilot population, fear of } \\
\text { uncertainty and trust in e-commerce were found to be } \\
\text { antecedents of perceived risk in e-commerce, making } \\
\text { perceived risk a mediator between these two variables and } \\
\text { the intention to buy online. }\end{array}$ \\
\hline
\end{tabular}




\begin{tabular}{|c|c|c|c|}
\hline $\begin{array}{l}\text { Chen and Holsapple } \\
{[36] .}\end{array}$ & $\begin{array}{l}\text { E-business adoption research: } \\
\text { State of the art. }\end{array}$ & 2013 & $\begin{array}{l}\text { This study undertakes a full examination of the e-business- } \\
\text { adoption area, focusing on } 618 \text { journal articles that deal } \\
\text { with e-business adoption. These are coded and analyzed } \\
\text { along multiple dimensions, including journal distribution, } \\
\text { units of analysis, data source regions (geographic focus } \\
\text { and economic focus), research method, and research } \\
\text { theme. Additionally, by comparing their results with those } \\
\text { of prior studies, new trends in e-business-adoption } \\
\text { research are detected by linking the five dimensions, } \\
\text { practical implications for e-business adoption researchers } \\
\text { are also provided. }\end{array}$ \\
\hline $\begin{array}{l}\text { Machfud and Kartiwi } \\
{[121] .}\end{array}$ & $\begin{array}{l}\text { E-commerce adoption by } \\
\text { Indonesian small } \\
\text { agribusiness: Reconsidering } \\
\text { the innovation-decision } \\
\text { process model. }\end{array}$ & 2013 & $\begin{array}{l}\text { This paper discusses and proposes Rogers model } \\
\text { incorporating all elements of the innovation-decision } \\
\text { process model including the stages of innovation-decision } \\
\text { and its influencing factors such as prior conditions, } \\
\text { communication channels, characteristics of the adopter, } \\
\text { and the perceived characteristics of e-commerce to gain a } \\
\text { better understanding on e-commerce adoption process. }\end{array}$ \\
\hline Sila [178]. & $\begin{array}{l}\text { Factors affecting the adoption } \\
\text { of B2B e-commerce } \\
\text { technologies. }\end{array}$ & 2013 & $\begin{array}{l}\text { The objective of this study is to analyze the factors } \\
\text { affecting the adoption of Internet-enabled business-to- } \\
\text { business electronic commerce (B2B EC) and test their } \\
\text { applicability in different contexts. The results showed that } \\
\text { all of the contextual variables, except country of origin, } \\
\text { influenced some of the adoption factors. The study shows } \\
\text { that the technology-organization-environment (TOE) } \\
\text { framework provides a strong foundation for the study of } \\
\text { B2B EC. }\end{array}$ \\
\hline $\begin{array}{l}\text { Wymer and Regan } \\
\text { [204]. }\end{array}$ & $\begin{array}{l}\text { Influential factors in the } \\
\text { adoption and use of E- } \\
\text { Business and E-commerce } \\
\text { Information technology (EEIT) } \\
\text { by small and medium } \\
\text { businesses. } \\
\end{array}$ & 2013 & $\begin{array}{l}\text { A number of differences were found among SMEs based } \\
\text { on demographic characteristics, particularly size and } \\
\text { industry-sector. }\end{array}$ \\
\hline $\begin{array}{l}\text { Ndayizigamiye and } \\
\text { McArthur [135]. }\end{array}$ & $\begin{array}{l}\text { Determinants of e-commerce } \\
\text { adoption amongst SMMEs in } \\
\text { durban, South Africa. }\end{array}$ & 2014 & $\begin{array}{l}\text { Using the Diffusion of Innovation Theory (DOI), this paper } \\
\text { examines the determinants of e-commerce adoption by } \\
\text { South African SMMEs in the Durban area. Findings reveal } \\
\text { that relative advantage and compatibility are the only DOI } \\
\text { variables that significantly influence the decision to adopt } \\
\text { e-commerce in Durban. Specifically, improving information } \\
\text { exchange with customers, easier access to international } \\
\text { markets, expansion of business reach, reduction of costs } \\
\text { of maintaining up to-date company information and } \\
\text { improving information exchange with suppliers are } \\
\text { significant factors that inform the decision to adopt e- } \\
\text { commerce in Durban. }\end{array}$ \\
\hline $\begin{array}{l}\text { Triandini, Djunaidy } \\
\text { and Siahaan [188]. }\end{array}$ & $\begin{array}{l}\text { Determining e-commerce } \\
\text { adoption level by SMEs in } \\
\text { Indonesia based on customer- } \\
\text { oriented benefits. }\end{array}$ & 2014 & $\begin{array}{l}\text { This study proposed a number of Indonesian SMEs' e- } \\
\text { commerce adoption levels and their ranks based on } \\
\text { customer-oriented benefits. Analysis result shows that } \\
\text { Indonesian SMEs can be classified into four levels of e- } \\
\text { commerce adoption based on customer-oriented benefits. }\end{array}$ \\
\hline $\begin{array}{l}\text { Ahmad, Abu Bakar, } \\
\text { Faziharudean, and } \\
\text { Zaki [7]. }\end{array}$ & \begin{tabular}{|l|} 
An Empirical Study of Factors \\
Affecting e-commerce \\
Adoption among Small- and \\
Medium-Sized Enterprises in a \\
Developing Country: Evidence \\
from Malaysia.
\end{tabular} & 2015 & $\begin{array}{l}\text { The findings show that e-commerce adoption within } \\
\text { Malaysian SMEs is affected by perceived relative } \\
\text { advantage, perceived compatibility, managers/owner's } \\
\text { knowledge and expertise, management characteristics, } \\
\text { and external change agents. }\end{array}$ \\
\hline $\begin{array}{l}\text { Kurnia, Karnali and } \\
\text { Rahim [107]. }\end{array}$ & $\begin{array}{l}\text { A qualitative study of } \\
\text { business-to-business } \\
\text { electronic commerce adoption } \\
\text { within the Indonesian grocery } \\
\text { industry: A multi-theory } \\
\text { perspective. }\end{array}$ & 2015 & $\begin{array}{l}\text { This study shows the usefulness of complementarily } \\
\text { deploying several adoption theories, and offers important } \\
\text { theoretical and practical implications for organizations as } \\
\text { they extend their supply chains globally. }\end{array}$ \\
\hline $\begin{array}{l}\text { Awiagah, Kang and Lim } \\
\text { [20]. }\end{array}$ & $\begin{array}{l}\text { Factors affecting e-commerce } \\
\text { adoption among SMEs in } \\
\text { Ghana. }\end{array}$ & 2016 & $\begin{array}{l}\text { The results indicate that government support has the } \\
\text { greatest direct impact on intentions to use e-commerce. } \\
\text { Managerial support and the influence of enabling and } \\
\text { regulatory conditions also play a vital role in stimulating } \\
\text { SME e-commerce adoption in Ghana. The results also } \\
\text { show that Ghanaian SMEs tend to imitate successful first- } \\
\text { movers to avoid the risks that attend e-commerce } \\
\text { technology. }\end{array}$ \\
\hline
\end{tabular}




\begin{tabular}{|c|c|c|c|}
\hline $\begin{array}{l}\text { Esmaeilpour, Hoseini } \\
\text { and Jafarpour [59]. }\end{array}$ & $\begin{array}{l}\text { An empirical analysis of the } \\
\text { adoption barriers of e- } \\
\text { commerce in small and } \\
\text { medium sized enterprises } \\
\text { (SMEs) with implementation of } \\
\text { technology acceptance model. }\end{array}$ & 2016 & $\begin{array}{l}\text { The results showed that organizational barriers, technical } \\
\text { barriers and environmental barriers as external factors on } \\
\text { technology has effected on two starter variables of } \\
\text { technology acceptance model that includes usefulness and } \\
\text { perceived ease and these predicted relationships are } \\
\text { confirmed. In addition, expressed relationships in the } \\
\text { Technology Acceptance Model (TAM), including the impact } \\
\text { of usefulness and perceived ease on attitude, impact of } \\
\text { attitude on Intention, and finally impact of Intention on } \\
\text { actual use was confirmed. }\end{array}$ \\
\hline $\begin{array}{l}\text { Jafari, Khatibzadeh and } \\
\text { Taj-Bornaee [91]. }\end{array}$ & $\begin{array}{l}\text { A multi-factor trust } \\
\text { management system based } \\
\text { on confidence in M-commerce } \\
\text { environment. }\end{array}$ & 2016 & $\begin{array}{l}\text { Trust plays an important role in the development and } \\
\text { profitability of users in mobile commerce systems. In order } \\
\text { to estimate the amount of trust, the variety of trust } \\
\text { management systems have been proposed and } \\
\text { implemented. One of the main challenges facing these } \\
\text { systems is the types of attacks that threaten them and their } \\
\text { impact on trust evaluation. In this paper, studied four } \\
\text { important attacks including new comer, Sybil, on-off and } \\
\text { reputation squeeze and also proposed a multi-factor trust } \\
\text { management system based on confidence. The proposed } \\
\text { model is simulated and results show that mean absolute } \\
\text { error (MAE) is decreased. }\end{array}$ \\
\hline $\begin{array}{l}\text { Kuswanto and } \\
\text { Sudarsono [108]. }\end{array}$ & $\begin{array}{l}\text { Perception of factors influence } \\
\text { on intention of adopting E- } \\
\text { Commerce with the business } \\
\text { value as intervening variable. }\end{array}$ & 2016 & $\begin{array}{l}\text { The objective of this study is to analyze the perception of } \\
\text { the factors that affect the intention of adopting e-commerce } \\
\text { by micro enterprises through the business value. The } \\
\text { factors include relative advantage, ease of use, security, } \\
\text { cost, managerial characteristic, external pressure, } \\
\text { managerial behavior towards e-commerce, and trust. The } \\
\text { results show that relative advantage, ease of use, } \\
\text { managerial characteristic, and trust influence on the } \\
\text { business value, while security, cost, external pressure, and } \\
\text { managerial behavior towards e-commerce do not. Next, } \\
\text { the business value influences on the intention of adopting } \\
\text { e-commerce. }\end{array}$ \\
\hline $\begin{array}{l}\text { Thanji and Vasantha } \\
\text { [187]. }\end{array}$ & $\begin{array}{l}\text { A study on drivers and barriers } \\
\text { of consumer adoption towards } \\
\text { E-Commerce offerings for } \\
\text { education. }\end{array}$ & 2016 & $\begin{array}{l}\text { Findings: Majority of the consumers are pushed towards } \\
\text { adoption due to time saving aspect while lack of required } \\
\text { technical skills stands out as major barrier. }\end{array}$ \\
\hline $\begin{array}{l}\text { Walker, Saffu and } \\
\text { Mazurek [199]. }\end{array}$ & $\begin{array}{l}\text { An Empirical Study of Factors } \\
\text { Influencing E-Commerce } \\
\text { Adoption/Non-Adoption in } \\
\text { Slovakian SMEs. }\end{array}$ & 2016 & $\begin{array}{l}\text { Adoption and non-adoption factors of } 230 \text { Slovakian SMEs } \\
\text { were empirically examined using logistic regression. } \\
\text { Compatibility and Organizational Readiness, Decision and } \\
\text { Operational Aids, and External Pressure were significant } \\
\text { for discerning e-commerce adoption. }\end{array}$ \\
\hline
\end{tabular}

Source: Own elaboration prepared based on the sources mentioned in the table

Table 4 displays a series of factors that, according to the authors mentioned, enable and encourage e-commerce adoption. With the intention of higlighting recurrent e-commerce adoption factors, Figure 13 shows the ones identified by the authors consulted in chronological order:

The figure 13 allows to observe that during the last decade the studies about the identification of e-commerce adoption factors have been prolific and demonstrated their evolution around diverse organization characteristics. It is worth emphasizing that in the early years (2006 and 2007) varied factors involving both organizational and technical aspects were identified. Research in the field has gradually advanced, going from studies that explored the technical factors to studies based on technology adoption and acceptance models (TAM), as well as on consumer behavior models (TPB) (2007-2010). Research has as well included studies intending to explain the identification of these factors through an articulated model (TOE), and the ones that have identified the importance of a suitable governmental structure as a mediating factor that impels e-commerce adoption, especially in developing countries (2010-2016). Based on Table 4 and Figure 13, we next generate a research agenda intending to guide the study of adoption factors in e-commerce in order to demolish barriers around this technology to access the benefits that it promises. 


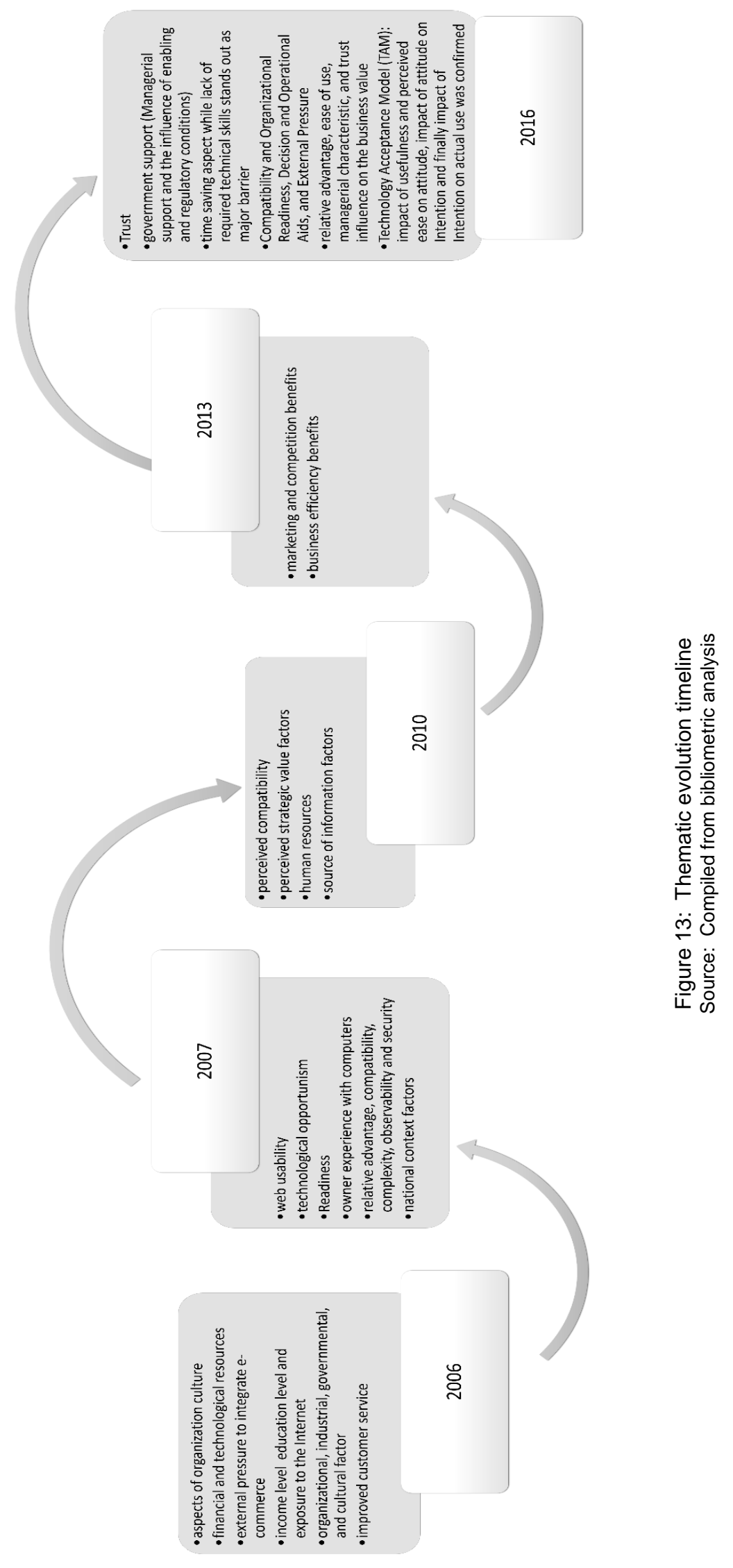




\section{Research Agenda}

Based on Table 4 and Figure 13, we present a research agenda that provides recommendations about the factors that should be taken into account in the adoption of e-commerce. This agenda is intended as a guideline for future investigation.

1. In first place, key aspects identified in the adoption of e-commerce are the role of the organization managers, and its organizational culture and structure. In this regard, organizations that count on financial and technical resources and have a flexible structure are more likely to taking risks and adopting e-commerce as part of their strategy.

2. Regarding the factors that stimulate e-commerce adoption in small and medium sized enterprises, findings point to the importance of considering technological opportunism and readiness, owner experience with computers, support within the organization, relative advantage, and compatibility [182]. In addition, factors related to the national context have been found to have a significant impact in the adoption of e-commerce in certain countries. In countries such as Malesia and Indonesia, for example, e-commerce has been affected by perceived relative advantage, perceived compatibility, manager/owner's knowledge and expertise, management characteristics and external change agents.

3. Some results point out the importance of considering gender factors influencing e-commerce adoption. In this regard, the influence of social norms is stronger in the female group while the influence of enjoyment is stronger in the male group. Regarding B2B e-commerce adoption, some findings indicate that education level along with exposition to Internet use become significant predictors to explain the rate of adoption of this new technology.

4. Regarding research methodologies to study e-commerce adoption factors, statistical analysis, structural equations, as well as models such as TAM and theories like DOI, findings of some studies indicate that marketing and competition benefits, essential benefits that support strategy and development, and business efficiency benefits all positively contribute to decisions that lead to an advanced level of e-commerce being adopted.

5. Finally, future work to be considered includes a meta-analysis or a systematic review of literature about the adoption of e-commerce in SMEs in emerging economies, in order to propose a model for it in accordance with the economic and social context, and the limitations of SMEs in such economies. On the other hand, a comparative analysis among the most used models in the evaluation of the adoption of e-commerce (Technology Acceptance Model; Theory of Planned Behavior; and more recently the technological framework model, Technology-Environmental-Organizational Framework, is recommended to put forward a unified integrative model that compiles the findings in this research field.

We would like to note the importance of making e-commerce a value generating tool in small and medium sized enterprises, considering that such enterprises constitute the $95 \%$ of the productive apparatus in developing countries. This could be achieved and consolidated through the strengthening of organizational processes, building flexible structures that permit an adequated level of risk in order to introduce this type of technology. In addition, since ecommerce adoption is a social process, the study of the factors that allow it in the market of small and medium sized enterprises should integrate qualitative and quantitative research methodologies.

\section{Conclusions}

The analysis evidenced that the study of factors of adoption of e-commerce is developing significantly in small and medium sized enterprises, due to them being most prone to the implementation of this commercial channel. Current studies are being conducted in a focused way in emerging economies, because it is in these countries where SMEs make up a large proportion of the business sector. With regards to the slow adoption of e-commerce in small businesses, they are attributed to various barriers that relate to perception of adoption and economic obstacles to invest in technology. A decisive factor in adopting e-commerce is perceived ease, this being a predictor of behavior for consumer purchases via the Internet. On the other hand, increased acceptance in the adoption of technology by consumers can be positively affected by the use of smart phones, because of its flexibility and ease of use, in addition to the installed capacity of banks to support credit card transactions, while still being complex, given that purchasing power becomes an important factor to prevent consumers from making transactions online.

It was possible to observe through the bibliometric analysis that great importance on the research field of e-commerce lies currently on the analysis of the processes of adoption of e-commerce in small and medium-sized companies in emerging countries, using robust models as the TAM, the Theory of Planned Behavior (TPB), and more recently, the TOE. On the other hand, statistical analysis through structural equations stands as the main form of analysis of 
information reported by research on the factors influencing the adoption of e-commerce; this is important because it constitutes a statistically robust tool to shape these factors and their role in the use of e-commerce. Finally, a strong interest is emerging in implementing e-commerce in the management of the supply chain through logistics providers, using it as an alternative that has resulted in benefits and high levels of productivity in companies.

With respect to the factors that favor the adoption of e-commerce, the following were identified: prior use of Information and Communication Technology (ICT) in the company personnel, the existence of national policies in support of ecommerce, the size of businesses, the level of maturity in the implementation of ICT in organizations, the provision of financial and technological resources for the implementation process of e-commerce, external pressure to be part of this type of trade, and possibilities for external assistance (advice or support) to implement e-commerce platforms.

Regarding the classification of e-commerce by type of transaction (see Table 1), the analysis indicates that the mode reporting more research is business-to-business (B2B) in emerging economies, which is linked to the growth in Internet users in emerging countries. This evidence the need for the business sector in emerging economies to increasingly adopt E-commerce among their strategies for market expansion. Among the factors that influence this process are the growth of the company, business history, recognition of the company by consumers, and the marketing strategies they use to reach potential customers.

It was observed that decreasing research fields (electronic markets, consumer behavior, social theory, economic analysis) focus on macro variables in the context of adoption of e-commerce. The decreasing interest of researchers on those aspects of the study of the adoption of e-commerce may be explained by the fact that research has (1) focused and specialized in particular factors that determine their use, and (2) oriented towards the perception and satisfaction of the business sector and consumers with the variables involved in its adoption. Among those variables are perceived confidence, attitude towards the use, and perceived ease of use, perceived usefulness, safety, and innovativeness.

The bibliometric analysis results show a growth in interest in the subject since 2001, 2006 being one of the most productive years with 38 published articles. With respect to publications, the Proceedings of the International Conference on Electronic Business (ICEB) was found to be of significant interest, compiling disclosures made within the framework of the conference, where technology issues involving E-commerce are discussed. That includes platforms, web services, knowledge models for e-commerce for the environment and for the company, as well as the peculiarities of the different applications of this technology.

The analysis of the law of productivity concludes that there is no Pareto Law, since $71.48 \%$ of the journals published $80 \%$ of the items, so we proceeded to separate the percentage of journal by quartile, obtaining that $8.20 \%$ of journals published $25 \%$ of the articles; presenting a marked increase in the proportion, $28.52 \%$ of the journals published $50 \%$ of the articles; and finally, the statistics showed that $64.45 \%$ of the journals published $75 \%$ of the articles. This indicates that knowledge is scattered in various related scientific journals in the area of Information Technology and Communication and there are no academic journals that have a significant concentration of studies on the topic of ecommerce adoption factors.

The author with highest productivity was found to be Robert MacGregor, Associate Professor in the School of Informatics and Computer Science at the University of Wollongong in Australia. His research expertise covers the area of information technology (IT) and electronic commerce (e-commerce) in small and medium enterprises (SMEs). Regarding the impact of publications on the subject, Chwelos, P (2001) tops the list with 489 citations; the paper presents results of an investigation of a parsimonious model that postulates three factors as determinants of adoption of electronic data interchange (EDI): provision, perceived benefits and external pressure. The authors conclude that external pressure and readiness are considerably more important than perceived benefits. The journal with the greatest impact is Information Systems Research (ISR), with 164 citations. ISR is an international journal that focuses on theories, developments and research on information systems in fields such as organizations, economy, and society in general.

\section{Limitations}

Among the main limitations of bibliometrics is the lack of a solid theoretical background supporting the construction of bibliometric analyses, which implies difficulties to generate strong enough indicators and leaves the inclusion and interpretation of a large part of the indicators to the criteria of researchers. On the other hand, dependence on a particular data base causes the risk of leaving aside journals which might be too recent to have been indexed or journals that have decided to get indexed in a different data base, which reduces the scope of information to be accessed.

The definition of systematic search equations, requires the analysis of information structures in data bases, which hinders the search in unpublished papers or papers published in lower quality journals or events, as well as in grey literature in the field of knowledge. Consequently, access to knowledge generated through other scientific dissemination media is left aside. A similar situation occurs with the language since main scientific data bases include 
a larger proportion of journals in English and restrict the possibility to access findings of research published in other languages.

\section{Acknowledgments}

We gratefully acknowledge the Instituto Tecnológico Metropolitano - ITM, the Faculty of Economics and Administrative Sciences and the Master in Management of Technological Innovation, Cooperation and Regional Development, for their support.

\section{References}

[1] C. Abbad, M. M. Morris and D. De Nahlik, Looking under the bonnet: Factors affecting student adoption of elearning systems in Jordan, The International Review of Research in Open and Distributed Learning, vol. 10, no. 2, pp. 1-25, 2009.

[2] A. Abdulghader, D. S. V. Singh and I. Mohamed, Impeding barriers for e-commerce adoption in Libya, Journal of Theoretical and Applied Information Technology, vol. 31, no. 2, pp. 129-133, 2011.

[3] M. G. Aboelmaged, Predicting e-readiness at firm-level: An analysis of technological, organizational and environmental (TOE) effects on e-maintenance readiness in manufacturing firms, International Journal of Information Management, vol. 34, no. 5, pp. 639-651, 2014.

[4] M. Abou-Shouk, P. Megicks and W. M. Lim, Perceived benefits and e-commerce adoption by SME travel agents in developing countries evidence from Egypt, Journal of Hospitality and Tourism Research, vol. 37, no. 4, pp. 490-515, 2013

[5] ACM, Association for computing machinery. (2015) International Conference Proceeding Series. ACM. [Online]. Available: http://www.acm.org/publications/icp series/

[6] R. Agarwal and J. Prasad, Are individual differences germane to the acceptance of new information technologies? Decision Sciences, vol. 30, no. 2, pp. 361-391, 1999.

[7] S. Z. Ahmad, A. R. Abu Bakar, T. M. Faziharudean, and K. A. Mohamad Zaki, An empirical study of factors affecting e-commerce adoption among small-and medium-sized enterprises in a developing country: Evidence from Malaysia, Information Technology for Development, vol. 21, no. 4, pp. 555-572, 2015.

[8] M. Ajzen and I. Fishbein, Understanding Attitudes and Predicting Social Behavior. Englewood Cliffs: Prentice Hall, 1980.

[9] M. Al Noor and B. R. Arif, Adoption of B2B e-commerce by the SMEs in Bangladesh, The International Institute for Science, Technology and Education (IISTE), vol. 2, no. 6, pp. 48-59, 2011.

[10] A. A. Al-Bakri and M. I. Katsioloudes, The factors affecting e-commerce adoption by Jordanian SMEs, Management Research Review, vol. 38, no. 7, pp. 726-749, 2015.

[11] W. Alrawabdeh, Factors impacting the adoption of e-commerce by microfinance companies in Jordan, Aktual'ni Problemy Ekonomiky= Actual Problems in Economics, vol. 179, no. 5, pp. 160-170, 2016.

[12] S. A. Al-Somali, R. Gholami and B. Clegg, An investigation into the adoption of electronic commerce among Saudi Arabian SMEs, Journal of Electronic Commerce in Organizations, vol. 9, no. 2, pp. 41-65, 2011.

[13] B. Al-Somali, S. A. Gholami and R. Clegg, An investigation into the factors affecting e-commerce adoption decisions by SMEs: A study in Saudi Arabia, in Strategic E-Commerce Systems and Tools for Competing in the Digital Marketplace (Khosrow-PourM, Ed.). Auston, United States of American, 2015, pp. 206-243.

[14] M. R. Amin and H. Hussin, E-commerce adoption in SME retail sector: A conceptual model, en information and communication technology for the muslim world (ICT4M), in Proceedings The 5th International Conference on, Kuching: 2014, pp. 1-6.

[15] W. Andrews, E-Commerce, real strategies, real benefits, United States of America, Gartner Group, September, vol. 17, 2002.

[16] É. Archambault, D. Campbell, Y. Gingras, and V. Larivière, Comparing bibliometric statistics obtained from the Web of Science and Scopus, Journal of the Association for Information Science and Technology, vol. 60, no. 7, pp. 1320-1326, 2009.

[17] L. Arguimbau-Vivó, E. Fuentes-Pujol and M. Gallifa-Calatayud, Una década de investigación documental sobre cienciometría en España: Análisis de los artículos de la base de datos ISOC (2000-2009), Revista Española de Documentación Científica, vol. 36, no. 2, p. 007, 2013.

[18] N. C. Astuti and R. A. Nasution, Technology readiness and e-commerce adoption among entrepreneurs of SMEs in Bandung City, Indonesia., Gadjah Mada International Journal of Business, vol. 16, no. 1, pp. 69-88, 2014.

[19] H. O. Awa, O. U. Ojiabo and B. C. Emecheta, Integrating TAM, TPB and TOE frameworks and expanding their characteristic constructs for e-commerce adoption by SMEs, Journal of Science and Technology Policy Management, vol. 6, no. 1, pp. 76-94, 2015.

[20] J. I. Awiagah, R., Kang and J. Lim, Factors affecting e-commerce adoption among SMEs in Ghana, Information Development, vol. 32, no. 4, pp. 815-836, 2016.

[21] M. S. Azam, M. Quaddus and others, How organisational characteristics explain the adoption of e-commerce by the SMEs in Bangladesh? in Proceedings of the 20th Australasian Conference on Information Systems (ACIS), Melbourne, 2009, pp. 03-05. 
[22] J. Bao and X. Sun, A Conceptual Model of Factors Affecting e-Commerce Adoption by SMEs in China, in Proceedings Management of e-Commerce and e-Government (ICMeCG), 2010 Fourth International Conference on, Chengdu, 2010, pp. 172-175.

[23] P. A. Barbonis and S. Laspita, Some factors influencing adoption of e-commerce in Greece, in Proceedings 2005 IEEE International Engineering Management Conference, Newfoundland and Labrador, 2005, pp. 31-35.

[24] P. E. Bertea and A. Zait, Perceived risk vs. intention to adopt e-commerce-a pilot study of potential moderators, Market-Tržište, vol. 25, no. 2, pp. 213-229, 2013.

[25] M. I. Bin Illyas Tan and I. S. bt Ibrahim, A survey on supply chain management and e-commerce technology adoption among logistics service providers in Johor, World Academy of Science, Engineering and Technology, International Journal of Social, Behavioral, Educational, Economic, Business and Industrial Engineering, vol. 4, no. 5, pp. 517-522, 2010.

[26] R. Boateng, R. Heeks, A. Molla, and R. Hinson, Advancing e-commerce beyond readiness in a developing country: Experiences of Ghanaian firms, Journal of Electronic Commerce in Organizations, vol. 9, no. 1, pp. 116, 2011.

[27] R. Boateng, R. Hinson, R. Heeks, and V. Mbarika, A resource-based analysis of e-commerce in developing countries, in Proceedings European Conference on Information Systems, 2010, pp. 2-12.

[28] D. Camps, Limitaciones de los indicadores bibliométricos en la evaluación de la actividad científica biomédica, Colombia Médica, vol. 39, no. 1, pp. 74-79, 2008.

[29] D. P. Cardinali, Posibles estrategias para la promoción de publicaciones científicas regionales, in Proceedings II Encuentro Iberoamericano de Editores Científicos, Buenos Aires, 2010, p. 24.

[30] F. Carter and L. Bélanger, The utilization of e-government services: Citizen trust, innovation and acceptance factors, Information Systems Journal, vol. 15, no. 1, pp. 5-25, 2005.

[31] A. Cecere and E. Acatitla, El comercio electrónico (e-commerce): Una posible ventana de oportunidad para las firmas en los países en vías de desarrollo, Revista Internacional de Investigación y Docencia, vol. 1, no. 1, pp. $12-19,2016$.

[32] J. Chaffey, D. Ellis-Chadwic and F. Mayer, E-Business and E-Commerce Management, 4th edition. London: Financial Ti- mes Prentice Hall, 2009.

[33] D. Chaffey, E-Business and E-Commerce Management Strategy, Implementation and Practice. Harlow: Fifth Pearson Education, 2011.

[34] S. C. Chan and M. T. Lu, Understanding Internet banking adoption and user behavior: A Hong Kong perspective, Lingnan University China, pp. 1-13, 2004.

[35] L. Chen and C. Holsapple, E-business adoption research: Analysis and structure, in Proceeding of the Eighteenth Americas Conference on Information Systems, Seattle, Washintong, pp. 1-10, 2012.

[36] L. Chen and C. W. Holsapple, E-business adoption research: State of the art, Journal of Electronic Commerce Research, vol. 14, no. 3, p. 261, 2013.

[37] J. K. Chen, N. A. Windasari and R. Pai, Exploring e-readiness on e-commerce adoption of SMEs: Case study South-East Asia, in Proceedings 2013 IEEE International Conference on Industrial Engineering and Engineering Management, Bangkok, 2013, pp. 1382-1386.

[38] J. Choi, A cross-cultural investigation of consumer e-shopping adoption: A comparison of Korean and American college students, Ph.D. dissertation, School the Ohio State University, pp. 1-210. 2001.

[39] V. Chooprayoon and C. C. Fung, Measuring Thai customer's gender and behaviours influence on the adoption of e-commerce technologies by small and medium enterprises (SMEs), International Association for development of the information society, in Procceding of de International Conference on E-Commerce, Amsterdam, the Netherlansd, 2008, pp. 1-8.

[40] V. Chooprayoon, C. C. Fung and A. A, Depickere, TECTAM, A modified technology acceptance model to assess e-commerce technologies adoption by Thai SME, in Proceedings TENCON 2007-2007 IEEE Region 10 Conference, Taipei, 2007, pp. 1-4.

[41] M.-L. Chuang and W. H. Shaw, A roadmap for successful e-business, in Proceedings Change Management and the New Industrial Revolution, 2001. IEMC'01, Albany, 2001, pp. 388-393.

[42] P. Chwelos, I. Benbasat and A. S. Dexter, Research report: Empirical test of an EDI adoption model, Information Systems Research, vol. 12, no. 3, pp. 304-321, 2001.

[43] W. J. Clinton and A. Gore, Framework for global electronic commerce, NASA, Washington, Technical Report $19980007208,1997$.

[44] R. G. Cuéllar and L. A. R. Tovar, Comercio electrónico en México: Propuesta de un modelo conceptual aplicado a las PyMES, Revista Internacional de Ciencias Sociales y Humanidades, SOCIOTAM, vol. 15, no. 1, pp. 79116, 2005.

[45] M. Cui and S. L. Pan, Developing focal capabilities for e-commerce adoption: A resource orchestration perspective, Information and Management, vol. 52, no. 2, pp. 200-209, 2015.

[46] F. Damanpour, Organizational innovation: A meta-analysis of effects of determinants and moderators, Academy of Management Journal, vol. 34, no. 3, pp. 555-590, 1991

[47] F. D. Davis, Perceived usefulness, perceived ease of use, and user acceptance of information technology, MIS Quarterly, vol. 13, no. 3, pp. 319-340, 1989.

[48] F. D. Davis, R. P. Bagozzi and P. R. Warshaw, User acceptance of computer technology: A comparison of two theoretical models, Management Science, vol. 35, no. 8, pp. 982-1003, 1989.

[49] R. Del Bosque and Á. H. Crespo, Antecedentes de la utilidad percibida en la adopción del comercio electrónico entre particulares y empresas, Cuadernos de Economía y Dirección de la Empresa, vol. 11, no. 34, pp. 107-134, 2008. 
[50] R. R. Dholakia and N. Kshetri, Factors impacting the adoption of the Internet among SMEs, Small Business Economics, vol. 23, no. 4, pp. 311-322, 2004.

[51] K. Dickersin, R. Scherer and C. Lefebvre, Identifying relevant studies for systematic reviews, BMJ, British Medical Journal, vol. 309, no. 6964, p. 1286, 1994.

[52] N. Durán and E. Grandón, Replica y comparación del codelo de McCloskey en el contexto Chileno-un estudio basado en el technology acceptance model (TAM), in Proceedings AMCIS 2006, Acapulco, 2006, p. 504.

[53] V. Durieux and P. A. Gevenois, Bibliometric indicators: Quality measurements of scientific publication 1, Radiology, vol. 255, no. 2, pp. 342-351, 2010.

[54] Y. Dwivedi and Z. Irani, Understanding the adopters and non-adopters of broadband, Communications of the ACM, vol. 52, no. 1, pp. 122-125, 2009

[55] M. S. Eastin, Diffusion of e-commerce: an analysis of the adoption of four e-commerce activities, Telematics and informatics, vol. 19, no. 3, pp. 251-267, 2002.

[56] S. Elahi and A. Hassanzadeh, A framework for evaluating electronic commerce adoption in Iranian companies, International Journal of Information Management, vol. 29, no. 1, pp. 27-36, 2009.

[57] B.V. Elsevier. (2016) Electronic commerce research and applications. Journal - Elsevier. [Online]. Available:: http://www.journals.elsevier.com/electronic-commerce-research-and-applications

[58] B. Eshraghi, A. Abu Osman, N.A. Gholizadeh, H. Ali, and S. Shadgan, 100 top-cited scientific papers in limb prosthetics, Biomedical Engineering Online, vol. 12, no. 119, 2013.

[59] Y. Esmaeilpour, M. Hoseini, and S. Y. Jafarpour, An empirical analysis of the adoption barriers of e-commerce in small and medium sized enterprises (SMEs) with implementation of technology acceptance model, Journal of Internet Banking and Commerce, vol. 21, no. 2, pp. 1-24, 2016.

[60] Z. Fang, E-government in digital era: Concept, practice, and development, International Journal of the Computer, the Internet and management, vol. 10, no. 2, pp. 1-22, 2002.

[61] E. Garbi, Alternative measures of performance for e-companies: A comparison of approaches, Journal of Business Strategies, vol. 19, no. 1, p. 1, 2002.

[62] Gartner. (2016, August) Technology research / gartner inc. Gartner. [Online]. Available: http://www.gartner.com/ technology/home.jsp.

[63] D. Gefen and D. W. Straub, The relative importance of perceived ease of use in IS adoption: A study of ecommerce adoption, Journal of the association for Information Systems, vol. 1, no. 1, p. 8, 2000.

[64] M. Ghobakhloo, D. Arias-Aranda, and J. Benitez-Amado, Adoption of e-commerce applications in SMEs, Industrial Management and Data Systems, vol. 111, no. 8, pp. 1238-1269, 2011.

[65] S. Ghobakhloo and M. Hong Tang, The role of owner/manager in adoption of electronic commerce in small businesses: The case of developing countries, Journal of small business and enterprise development, vol. 20, no. 4, pp. 754-787, 2013.

[66] A. Giddens, The Constitution of Society: Outline of the Theory of Structuration. California: Univ of California Press, 1984.

[67] A. Gläser, J. Glänzel and W. Scharnhorst, Same data-different results? Towards a comparative approach to the identification of thematic structures in science, Scientometrics, vol. 111, no. 2, pp. 981-998, 2017.

[68] J. Glückler, Knowledge, networks and space: Connectivity and the problem of non-interactive learning, Regional Studies, vol. 47, no. 6, pp. 880-894, 2013

[69] J. Gomez, I., Fernandez and M. T. Sebastian, Analysis of the structure of international scientific cooperation networks through bibliometric indicators, Scientometrics, vol. 44, no. 3, pp. 441-457, 1999.

[70] R. Govindaraju and D. R. Chandra, Analysis of level and barriers of e-commerce adoption by Indonesian small, medium, and micro enterprises (SMMEs), Internetworking Indones Journal, vol. 4, no. 1B, pp. 9-14, 2012.

[71] R. Govindaraju and D. R. Chandra, E-commerce adoption by Indonesian small, medium, and micro enterprises (SMMEs): Analysis of goals and barriers, in Proceedings Communication Software and Networks (ICCSN), 2011 IEEE 3rd International Conference on, Xi'an, 2011, pp. 113-117.

[72] E. E. Grandon, J. M. Pearson and W. Currie, Perceptions of strategic value and adoption of e-commerce: A theoretical framework and empirical test, Value Creat. E-Bus. Models Issues Perspect. Value Creat. E-Bus. Models Elsevier Oxford, pp. 1-14, 2004.

[73] E. E. Grandon, S. A. Nasco and P. P. Mykytyn, Comparing theories to explain e-commerce adoption, Journal of Business Research, vol. 64, no. 3, pp. 292-298, 2011.

[74] J. Gruen, T. W. Osmonbekov and T. Czaplewski, eWOM: The impact of customer-to-customer online know-how exchange on customer value and loyalty, Journal of Business research, vol. 59, no. 4, pp. 449-456, 2006.

[75] S. Gupta and B. M. Bhattacharya, A bibliometric approach towards mapping the dynamics of science and technology, DESIDOC Journal of Library and Information Technology, vol. 24, no. 1, pp. 3-8, 2004.

[76] A. Hajiha and L. Hajihashemi, Understanding electronic commerce adoption decision in Iranian small and medium enterprises: Integrating current theories, in Proceedings 2008 IEEE International Engineering Management Conference, Estoril, 2008, pp. 1-5.

[77] M. Hall, Publish and perish? Bibliometric analysis, journal ranking and the assessment of research quality in tourism, Tourism Management, vol. 32, no. 1, pp. 16-27, 2011.

[78] G. Hernández, Las redes de colaboración científica y su efecto en la productividad. Un análisis bibliométrico, Bibliotecología e Información, vol. 27, no. 59, pp. 159-175, 2013.

[79] Á. Hernández-García, S. Iglesias-Pradas, J. Chaparro-Peláez, and F. Pascual-Miguel, Perceived compatibility and the adoption of B2C e-commerce by non-buyers, in World Summit on Knowledge Society, Ph.D. thesis, Universidad Politecnica de Madrid España, pp. 186-192, 2010. 
[80] A. Herrero, I. Rodríguez del Bosque and M. M. García de los Salmones, La compatibilidad percibida en la adopción del comercio electrónico B2C: Un análisis sobre la base del Modelo de Aceptación de Tecnología, in Proceedings Actas del XIV Congreso Nacional de ACEDE, Murcia, 2004, pp. 1-30

[81] F. Herzallah and M. Mukhtar, Organization information ecology and e-commerce adoption: Effect on organizational SMEs performance, Journal of Computer Science, vol. 11, no. 3, p. 540, 2015.

[82] K. Hong and W. Zhu, Migrating to internet-based e-commerce: Factors affecting e-commerce adoption and migration at the firm level, Information and Management, vol. 43, no. 2, pp. 204-221, 2006.

[83] Z. P. Hou and Y. Y. Li, A Bibliometric analysis of electronic commerce research from 1996 to 2012, Applied Mechanics and Materials, vol. 644, pp. 5777-5780, 2014

[84] C. Hsu and C. W. Yeh, Understanding the factors affecting the adoption of the internet of things, Technology Analysis and Strategic Management, vol. 29, no. 9, pp. 1-14, 2016.

[85] X. Hu, Research on the impact of B2C e-commerce and third party platform: An empirical analysis based on factor analysis, International Journal of Smart Home, vol. 10, no. 3, pp. 315-324, 2016.

[86] Y. Hwang, An empirical investigation of normative, affective, and gender influence on e-commerce systems adoption, in Proceedgins AMCIS, Lima, 2010, p. 37

[87] F. Iddris, Adoption of e-commerce solutions in small and medium-sized enterprises in Ghana, European Journal of Business and Management, vol. 4, no. 10, pp. 48-57, 2012.

[88] IGI Global Disseminator of Knowledge. (2003) Journal of electronic commerce in organizations (JECO). IGI Global Disseminator of Knowledge. [Online]. Available: http://www.igi-global.com/journal/journal-electroniccommerce-organizations-jeco/1076.

[89] IGI Global Disseminator of knowledge. (2016, August) Robert MacGregor | IGI Global, 2016-1988. IGI Global. [Online]. Available: http://www.igi-global.com/affiliate/robert-macgregor/597.

[90] IJEC, International journal of electronic commerce. (2016) Journal underestanding and proactice of electronic commerce. IJEC. [Online]. Available: http://www.ijec-web.org/

[91] Z. T. Jafari, S, Khatibzadeh and L. Bornaee, A multi-factor trust management system based on confidence in $\mathrm{m}$ commerce environment, in Proceedings Technology, Communication and Knowledge (ICTCK), 2015 International Congress on, Mashhad, Iran, 2015, pp. 524-529.

[92] J. Jansson, Consumer eco-innovation adoption: assessing attitudinal factors and perceived product characteristics, Business Strategy and the Environment, vol. 20, no. 3, pp. 192-210, 2011

[93] C. Jones, M. V. Alderete and J. Motta, Adoption of e-commerce in micro, small, and medium-sized commercial and service enterprises in Córdoba, Argentina, Cuadernos de Administración (Universidad del Valle), vol. 29, no. 50 , pp. $154-175,2013$

[94] L. Junwei and L. Huashen, Factors constraining the adoption of e-commerce among China's small and mid-sized enterprises, in Proceedgins The 2nd International Conference on Information Science and Engineering, Hangzhou, 2010, pp. 1-4.

[95] C. Jurasinski, G. Retzer and V. Beierkuhnlein, Inventory, differentiation, and proportional diversity: A consistent terminology for quantifying species diversity, Oecologia, vol. 159, no. 1, pp. 15-26, 2009.

[96] S. Kabanda, Power dynamics in e-commerce adoption in least developing countries: The case of dar-es-salaam SMEs, Tanzania, in Proceedgins International Conference on e-Infrastructure and e-Services for Developing Countries, Zanzibar, 2011, pp. 218-227.

[97] I. Kabanda and S. Brown, A structuration analysis of small and medium enterprise (SME) adoption of e-commerce: The case of Tanzania, Elematics and Informatics, vol. 34, no. 4, pp. 118-132, 2017.

[98] D. Kabongo and J. O. okpara, ICT possession among Congolese SMEs: An exploratory study, Journal of Small Business and Enterprise Development, vol. 21, no. 2, pp. 313-326, 2014.

[99] M. Kapurubandara and R. Lawson, SMEs in developing countries face challenges in adopting e-commerce technologies, in Proceedings 2007 Inaugural IEEE-IES Digital EcoSystems and Technologies Conference, Cairns, Australia, 2007, pp. 141-146.

[100]M. Kapurubandara and R. Lawson, SMEs in developing countries need support to address the challenges of adopting e-commerce technologies, in Proceedgins 20th Bled eConference eMergence: Merging and Emerging Technologies, Processes, and Institutions, Bled, Slovenia, 2007, pp. 485-499.

[101]R. J. Karnali and S. Kurnia, The adoption of B2B e-commerce initiatives by the Indonesian grocery industry, in Proceddings PACIS, Brisbane, 2011, p. 86.

[102] M. Kartiwi and T. S. Gunawan, Assessment of e-commerce adoption benefits by Indonesian women entrepreneurs, in Proceddings Information and Communication Technology for the Muslim World (ICT4M), 2013 5th International Conference on, Rabat, Morocco, 2013, pp. 1-4.

[103] A. Kasraian and L. Faed, E-eagerness leverages on the breakthrough of e-commerce in the public sector: Case study of Khuzestan aater and power authority of Iran 1, in Proceedings E-Business Engineering (ICEBE), 2010 IEEE 7th International Conference on, Shanghai, 2010, pp. 358-363.

[104]R. J. Kauffman, J. McAndrews and Y.-M. Wang, Opening the black box of network externalities in network adoption, Information Systems Research, vol. 11, no. 1, pp. 61-82, 2000.

[105]J. King and W. R. He, A meta-analysis of the technology acceptance model, Information and management, vol. 43, no. 6, pp. 740-755, 2006.

[106]A. Kolsaker, L. Lee-Kelley, A. S. Lau, and V. W. Kwok, How e-government strategies influence e-commerce adoption by SMEs, Electronic Government, an International Journal, vol. 4, no. 1, pp. 20-42, 2007

[107] S. Kurnia, R. J. Karnali and M. M. Rahim, A qualitative study of business-to-business electronic commerce adoption within the Indonesian grocery industry: A multi-theory perspective, Information and Management, vol. 52, no. 4, pp. 518-536, 2015. 
[108]A. Kuswanto, Perception of factors influence on intention of adopting e-commerce with the business value as intervening variable, Advanced Science Letters, vol. 22, no. 5-6, pp. 1614-1617, 2016.

[109] R. D. Lamie, D. L. Barkley, D. M. Markley, and others, Positive examples and lessons learned from rural small business adoption of e-commerce strategies, Journal of Extension, vol. 49, no. 6, p. 6, 2011.

[110]K. Lee and C. M. Cheung, Internet retailing adoption by small-to-medium sized enterprises (SMEs): A multiplecase study, Information Systems Frontiers, vol. 6, no. 4, pp. 385-397, 2004.

[111] J. W. Lian, D. C. Yen and Y. T. Wang., An exploratory study to understand the critical factors affecting the decision t0o adopt cloud computing in Taiwan Hospital, International Journal of Information Management, vol. 34, no. 1, pp. 28-36, 2014

[112] T. Lip-Sam and L. Hock-Eam, Estimating the determinants of B2B e-commerce adoption among small and medium enterprises, International journal of business and society, vol. 12, no. 1, p. 15, 2011.

[113]S. Liu and Z. Deng, How environment risks moderate the effect of control on performance in information technology projects: Perspectives of project managers and user liaisons, International Journal of Information Management, vol. 35, no. 1, pp. 80-97, 2015

[114]F. Lucking-Reiley and D. Spulber, Business-to-business electronic commerce, The Journal of Economic Perspectives, vol. 15, no. 1, pp. 55-68, 2001

[115] J. C. Y. Luna, Mlearning: La aceptación tecnológica como factor crítico del desarrollo de modelos de negocio de formación online, Ph.D. dissertation, Universitat Rovira I Virgili, Departamento de Gestión de Empresas, Tarragona, 2015.

[116]A. Luqman, N. K. Abdullah and M. A. Ghapar, Modeling the adoption of e-business amongst SMEs in Terengganu, in Proceedings Humanities, Science and Engineering (CHUSER), 2011, IEEE Colloquium on, Penang, 2011, pp. 459-464.

[117] R. C. MacGregor and L. Vrazalic, E-commerce adoption barriers in small businesses and the differential effects of gender, Journal of Electronic Commerce in Organizations, vol. 4, no. 2, 2009.

[118]R. MacGregor and L. Vrazalic, Strategic Alliances and E-Commerce Adoption in Regional SMEs: A Comparative Study of Swedish and Australian Regional SMEs, In Strategic Use of Information Technology for Global Organizations pp. 156-200, 2007

[119]R. C. MacGregor and M. Kartiwi, Perception of barriers to e-commerce adoption in SMEs in a developed and developing country: A comparison between Australia and Indonesia, Journal of Electronic Commerce in Organizations, vol. 8, no. 1, pp. 61-82, 2010

[120] J. Macharia, Factors affecting the adoption of e-commerce in SMEs in Kenya, International Journal of Technology Intelligence and Planning, vol. 5, no. 4, pp. 386-401, 2009

[121]K. Machfud and M. Kartiwi, E-commerce adoption by Indonesian small agribusiness: Reconsidering the innovation-decision process model, in Proceedings Information and Communication Technology for the Muslim World (ICT4M), 2013 5th International Conference on, Rabat, Morocco, 2013, pp. 1-6.

[122] C. A. F. Madrid II and De la Gala Sánchez, Análisis bibliométrico de la productividad científica en la revista Mapfre Medicina, Mapfre Medicina, vol. 12, no. 3, pp. 157-167, 2001.

[123] S. R. Magal, P. Koslage and N. M. Levenburg, Towards a stage model for e-business adoption among SMEs: Preliminary results for manufacturing and service firms, in Proceedings AMCIS 2008 Proceedings, Toronto, 2008, p. 148.

[124] S. Mahendra and M. Yoshiki, A bibliometric analysis on online shopping, International Journal of E-Education, EBusiness, E-Management and E-Learning, vol. 5, no. 2, p. 55, 2015.

[125] Martins and T. Oliveira, Determinants of e-commerce adoption by small firms in Portugal, in Proceedings of the 3rd European conference on information management and evaluation, Gothenburg, 2009, pp. 328-338.

[126] Y. Y. Maryeni, R. Govindaraju, B. Prihartono, and I. Sudirman, Technological and organizational factors influencing the e-commerce adoption by Indonesian SMEs, in Proceddings Management of Innovation and Technology (ICMIT), 2012 IEEE International Conference on, 2012, pp. 436-441.

[127] T. Maswera, R. Dawson, and J. Edwards, E-commerce adoption of travel and tourism organisations in South Africa, Kenya, Zimbabwe and Uganda, Telematics and Informatics, vol. 25, n.o 3, pp. 187-200, 2008.

[128] A. Menascé, D. A., Almeida, V. A., Fonseca, R., and Mendes, A methodology for workload characterization of ecommerce sites., in In Proceedings of the 1st ACM conference on Electronic commerce, Denver, 1999, pp. 119128.

[129]P. Merhi and M. Ahluwalia, Influence of Safety Nets, Uncertainty Avoidance, and Governments on E-Commerce Adoption: A Country-Level Analysis, Juornal International Business Studies, vol. 35, n. 6, pp. 545-559, 2017.

[130]E. Michaelian, M. Hogg, E. H. Hall, and R. J. Arsenault, Massive mortality of aspen following severe drought along the southern edge of the Canadian boreal forest., Global Change Biology, vol. 17, no. 6, pp. 2084-2094, 2011.

[131]S. Miguel, Revistas y producción científica de América Latina y el Caribe: Su visibilidad en SciELO, RedALyC y SCOPUS, Revista Interamericana de Bibliotecología, vol. 34, no. 2, pp. 187-199, 2011.

[132] P. Mohammed and Z. A. Tejay, Examining privacy concerns and ecommerce adoption in developing countries: The impact of culture in shaping individuals' perceptions toward technology, Computers and Security, vol. 67, pp. 254-265, 2017

[133]S. Molla and A. Licker, Perceived e-readiness factors in e-commerce adoption: An empirical investigation in a developing country, International Journal of Electronic Commerce, vol. 10, no. 1, pp. 83-110, 2005.

[134] M. S. Nathan and R. J. Ahmed, Electronic commerce in the Arab world, in Handbook of Research on E-Services in the Public Sector: E-Government Strategies and Advancements: E-Government Strategies and Advancements (A. T. Al Ajeeli and Y. A. Latif Al-Bastaki, Eds.). Hershey: Information Science Reference, 2010, p. 214 
[135]P. Ndayizigamiye and B. McArthur, Determinants of e-commerce adoption amongst SMMEs in Durban, South Africa, Mediterranean Journal of Social Sciences, vol. 5, no. 25, p. 250, 2014

[136]E. W. Ngai and F. K. T. Wat, A literature review and classification of electronic commerce research, Information and Management, vol. 39, no. 5, pp. 415-429, 2002.

[137]D. Nickels and O. Kwun, The relationship between e-commerce adoption and organizational culture, in Proceedings AMCIS 2006 Proceedings, Acapulco, 2006, p. 42.

[138] M. Norris and C. Oppenheim, Comparing alternatives to the Web of Science for coverage of the social sciences' literature, Journal of informetrics, vol. 1, no. 2, pp. 161-169, 2007.

[139] A. O'cass and T. Fenech, Web retailing adoption: exploring the nature of internet users Web retailing behaviour, Journal of Retailing and Consumer services, vol. 10, no. 2, pp. 81-94, 2003.

[140] Y. Okubo, Bibliometric indicators and analysis of research systems, methods and examples, OECD Science, Technology and Industry, Paris, Working Papers 1997/01, 1997.

[141]W. Olatokun and M. Kebonye, E-commerce technology adoption by SMEs in Botswana, International Journal of Emerging Technologies and Society, vol. 8, no. 1, p. 42, 2010.

[142] A. Oludare Gabriel, K. Sushil, J. Zhang, and others, Factors affecting the adoption of e-commerce: a study in Nigeria, Journal of Applied Sciences, vol. 6, no. 10, pp. 2224-2230, 2006.

[143] M. G. Onofrio, The public CV database of Argentine researchers and the CV-minimum Latin-American model of standarization of CV information for $\mathrm{R}$ and $\mathrm{D}$ evaluation and policy-making, Research Evaluation, vol. 18, no. 2, pp. 95-103, 2009.

[144]G. Pappas, I. O. Kourouthanassis, P. E. Giannakos, and M. N. Lekakos, The interplay of online shopping motivations and experiential factors on personalized e-commerce: A complexity theory approach, Telematics and Informatics, vol. 34, no. 5, pp. 730-742, 2017.

[145]Y. Park, An analysis of the technology acceptance model in understanding university students' behavioral intention to use e-learning, Educational Technology and Society, vol. 12, no. 3, pp. 150-162, 2009.

[146]P. A. Pavlou and L. Chai, What drives electronic commerce across cultures? Across-cultural empirical investigation of the theory of planned behavior, Journal of Electronic Commerce Research, vol. 3, no. 4, pp. 240253, 2002.

[147] M. Pearson and E. E. Grandon, An empirical study of factors that influence e-commerce adoption/non-adoption in small and medium sized businesses, Journal of Internet Commerce, vol. 4, no. 4, pp. 1-21, 2006.

[148] G. Peláez, E. Cadavid and L. Awad, Propuesta metodológica para realizar una vigilancia tecnológica apoyada en un análisis topológico de redes de autores, Biblioteca Digital de la Asociación Latino-lberoamericana de Gestión Tecnológica, vol. 1, no. 1, 2013.

[149]F. Peng and S. Kurnia, Exploring the national context in electronic commerce adoption in developing countries, in Asia, Asia Pacific Journal of Management, vol. 22, no. 4, pp. 321-336, 2008.

[150] M. W. Peng, How Network Strategies and Institutional Transitions Evolve in Asia, Springer, Asia Pacific Journal of Management, vol. 22, no. 4, pp.321-336, 2005.

[151]N. Peña García, El valor percibido y la confianza como antecedentes de la intención de compra online: El caso colombiano, Cuadernos de Administración, vol. 30, no. 51, pp. 15-24, 2014.

[152] I. Phau and S. Meng Poon, Factors influencing the types of products and services purchased over the Internet, Internet Research, vol. 10, no. 2, pp. 102-113, 2000.

[153]A. Phelps, C. Heidl and R. Wadhwa, Knowledge, networks, and knowledge networks: A review and research agenda, Journal of Management, vol. 38, no. 4, pp. 1115-1166, 2012.

[154] H. Pięta, Theoretical, methodological and terminological issues in researching indirect translation: A critical annotated bibliography, Translation Studies vol. 10, no. 2, pp. 198-216, 2017.

[155] R. Piezzi, Políticas editoriales de instituciones y editoriales: Aquí y ahora de las ediciones científicas de la region, in Proceedings II Encuentro Iberoamericano de editores científicos, Washington, 2010, p. 1.

[156] C. Plana, N. Cerpa and P. B Bro, Bases para la creación de una metodología de adopción de comercio electrónico para las PYMES Chilenas, Revista Facultad de Ingeniería-Universidad de Tarapacá, vol. 14, no. 1, pp. 49-63, 2006.

[157] A. Pritchard, Statistical bibliography or bibliometrics, Journal of Documentation, vol. 25, no. 4, p. 348, 1969.

[158]F. Purcell, J. Toland and S. L. Huff, The potential of e-commerce for remotely located SMEs: Case studies from Samoa, in Electronic Commerce in Small to Medium-Sized Enterprises: Frameworks, Issues and Implications (N. A. Y. Al-Qirim, Ed.). USA: Idea Group Publishing, 2004, pp. 86-105.

[159]B. Qi and W. McGilligan, An investigation into e-commerce adoption profile for small and medium-sized enterprises in Bury Greater Manchester, UK, in Proceedings E-Commerce and Web Technologies, Greater Manchester, UK 2007, pp. 68-77.

[160] M. Quaddus and J. Xu, Adoption of e-commerce: A decision theoretic framework and an illustrative application, in Proceedings Computer and Information Technology, 2007, iccit 2007, 10th International Conference on, Dhaka, 2007, pp. 1-6.

[161]S. Quek, An Application of Dynamic Game Theory to the Study of E-Commerce. EUA: Addison Wesley, 2001.

[162] G. Reddick, Government e-commerce adoption: A study of Texas counties, Journal of E-Government, vol. 2, no. 2, pp. 45-73, 2006.

[163] F. Rinia, E. J. Van Leeuwen, T. N. Van Vuren, and H. G. Van Raan, Comparative analysis of a set of bibliometric indicators and central peer review criteria: Evaluation of condensed matter physics in the Netherlands, Research Policy, vol. 27, no. 1, pp. 95-107, 1998.

[164]B. Roberts and M. Mackay, IT supporting supplier relationships: The role of electronic commerce, European Journal of Purchasing and Supply Management, vol. 4, no. 2, pp. 175-184, 1998. 
[165]A. Rodríguez-Ardura and I. Meseguer-Artola, Toward a longitudinal model of e-commerce: Environmental, technological, and organizational drivers of B2C adoption, The Information Society, vol. 26, no. 3, pp. 209-227, 2010.

[166]M. Rogers, Everett, Diffusion of Innovations, New York: The Free Press, 1995.

[167] M. Rogers, The diffusion of innovations model, Nato Asi Series D Behavioural and Social Sciences, vol. 70, pp. 9-9, 1993.

[168] Y. Rouibah, K. Lowry and P. B. Hwang, The effects of perceived enjoyment and perceived risks on trust formation and intentions to use online payment systems: New perspectives from an Arab country, Electronic Commerce Research and Applications, vol. 19, no. 1, pp. 33-43, 2016.

[169]F. Rowe, D. Truex, M. Q. Huynh, and others, An empirical study of determinants of e-commerce adoption in SMEs in Vietnam: An economy in transition, Journal of Global Information Management JGIM, vol. 20, no. 3, pp. 23-54, 2012.

[170] G. Rueda, P. Gerdsri and D. F. Kocaoglu, Bibliometrics and social network analysis of the nanotechnology field, in Proceedings PICMET'07-2007 Portland International Conference on Management of Engineering and Technology, Portland, 2007, pp. 2905-2911.

[171]R. Salkute, Impact of functionalities on e-commerce in supply chain in India, International Journal of Business and Systems Research, vol. 4, no. 2, pp. 149-168, 2010.

[172]R. Sancho, Indicadores bibliométricos utilizados en la evaluación de la ciencia y la tecnología. Revisión bibliográfica, Revista Española de Documentación Científica, vol. 13, no. 3, p. 842, 1990.

[173] H. Seyal and M. M. Rahim, Understanding electronic commerce adoption in Bruneian SMEs: A Replication of the application of TAM and perceived strategic value models, Journal of Electronic Commerce in Organizations (JECO), vol. 8, no. 4, pp. 32-50, 2010.

[174] S. Shah Alam, A. Khatibi, M. Ismail Sayyed Ahmad, and H. Bin Ismail, Factors affecting e-commerce adoption in the electronic manufacturing companies in Malaysia, International Journal of Commerce and Management, vol. 17, no. 1/2, pp. 125-139, 2008.

[175] W. Sharma and G. Lijuan, Ethical perspectives on e-commerce: an empirical investigation, Internet Research, vol. 24, no. 4, pp. 414-435, 2014.

[176]B. Shi, An empirical study on small enterprises e-commerce adoption decision based on TAM Model and TOE framework, Advanced Materials Research, vol. 712, pp. 2521-2524, 2013.

[177] Y.-Y. Shih and K. Fang, The use of a decomposed theory of planned behavior to study Internet banking in Taiwan, Internet Research, vol. 14, no. 3, pp. 213-223, 2004.

[178] I. Sila, Factors affecting the adoption of B2B e-commerce technologies, Electronic Commerce Research, vol. 13, no. 2, pp. 199-236, 2013

[179]I. Sila, The state of empirical research on the adoption and diffusion of business-to-business e-commerce, International Journal of Electronic Business, vol. 12, no. 3, pp. 258-301, 2015.

[180]M. Y. Siyal, B. S. Chowdhry and A. Q. Rajput, The adoption of e-commerce by overseas sindhis: An empirical study, in Proceedings 2006 Innovations in Information Technology, Dubai, 2006, pp. 1-5.

[181]R. Song, S. M. Kim, E. Tang, and R. L. Bosselman, Exploring the determinants of e-commerce by integrating a technology-organization-environment framework and an expectation-confirmation model, Tourism Analysis, vol. 20, no. 6, pp. 689-696, 2015.

[182] L. Sparling, M. Toleman and A. Cater-Steel, SME adoption of e-commerce in the central okanagan region of Canada, in Proceedings ACIS 2007, Toowoomba, 2007, p. 95.

[183] C. Swatman and C. E. Chan, Commerce implantation in Australia. Australia: A Case Study Approach, 2001.

[184] M. Tarafdar and S. D. Vaidya, Challenges in the adoption of e-commerce technologies in India: The role of organizational factors, International Journal of Information Management, vol. 26, no. 6, pp. 428-441, 2006.

[185] F. Tavera and B. E. Londoño, Factores determinantes de la aceptación tecnológica del e-commerce en paises emergentes, Revista Ciencias Estratégicas, vol. 22, no. 31, pp. 101-119, 2014.

[186]F. Tavera and B. Londoño, Entornos Digitales: Escenarios para el marketing y nuevos modelos de negocio, Encuentro Internacional de Investigación en Administración, Encuentro de investigación Colombiana de facultades de administración, Desarrollo Regional Sostenible, una mirada Nacional e internacional, pp. 11-23, 2012.

[187] S. Thanji and M. Vasantha, A study on drivers and barriers of consumer adoption towards e-commerce offerings for education, Indian Journal of Science and Technology, vol. 9, no. 32, 2016.

[188] S. M. Thatcher, W. Foster, and L. Zhu, B2B e-commerce adoption decisions in Taiwan: The interaction of cultural and other institutional factors, Electronic Commerce Research and Applications, vol. 5, no. 2, pp. 92-104, 2006.

[189] M. Tornatzky, L. G., and Fleischer, The Processes of Technological Innovation. Lexiton, MA: Lexit. Books, 1990.

[190]E. Triandini, A. Djunaidy and D. Siahaan, Determining e-commerce adoption level by SMEs in Indonesia based on customer-oriented benefits, in Proceedings Information Technology, Computer and Electrical Engineering (ICITACEE), 2014 1st International Conference on, Semarang, 2014, pp. 281-285.

[191] H. T. Tsou and S. H. Y. Hsu, Performance effects of technology-organization-environment openness, service coproduction, and digital-resource readiness: The case of the IT industry, International Journal of Information Management, vol. 35, no. 1, pp. 1-14, 2015.

[192] J. Turban, E. and Lee, Electronic Commerce, a Managerial Perspective. EUA: Prentice Hall, 2002.

[193]J. Turban, J. K. Lee, D. King, T. P. Liang, and D. Turban, Electronic Commerce 2010. Bergen: Prentice Hall Press, 2009.

[194]V. Umadevi, Case study-centrality measure analysis on co-authorship network, ournal of Global Research in Computer Science, vol. 4, no. 1, pp. 67-70, 2013. 
[195]J. M. Vallejo, Y. P. Redondo and A. U. Acerete, Las características del boca-oído electrónico y su influencia en la intención de recompra online, Revista Europea de Dirección y Economía de la Empresa, vol. 24, no. 2, pp. 6175, 2015.

[196] S. Vatanasakdakul and J. D'Ambra, A conceptual model for e-commerce adoption in developing countries: A task-technology fit perspective, International Journal of Information Technology and Management, vol. 6, no. 24, pp. 343-361, 2007.

[197] V. Venkatesh and F. D. Davis, A theoretical extension of the technology acceptance model: Four longitudinal field studies, Management Science, vol. 46, no. 2, pp. 186-204, 2000.

[198]E. Villa, J. Valencia and A. Valencia, El papel de las narrativas digitales como nueva estrategia educativa: Resultados desde un análisis bibliométrico, Kepes, vol. 13, no. 13, pp. 197-231, 2016.

[199] M. Walker, J. H., Saffu and K. Mazurek, An empirical study of factors influencing e-commerce adoption/nonadoption in Slovakian SMEs, Journal of Internet Commerce, vol. 15, no. 3, pp. 189-213, 2016.

[200] R. T. Wigand, Electronic commerce: Definition, theory, and context, The information Society, vol. 13, no. 1, pp. 1-16, 1997.

[201]F. Wu, Bringing E to corporate America: the drivers of e-business adoption and its impact on firm performance, University of Texas Austin, pp. 79-116, 2001.

[202] M. Wu, L. Zhang, Q. Xing, L. Dai, and H. Du, A Study for understanding e-commerce adoption in China's service SMEs from web usability perspective, in Proceedings 2007 International Conference on Wireless Communications, Networking and Mobile Computing, Shangai, 2007, pp. 3420-3423.

[203] A. Wyckoff and A. Colecchia, The economic and social impact of electronic commerce: Preliminary findings and research agenda, Organization for Economic Coperation and Development pp. 21-43, 1999.

[204] S. Wymer and E. Regan, Influential Factors in the Adoption and Use of E-Business and E-Commerce Information Technology (EEIT) by Small and Medium Businesses, E-Commerce for Organizational Development and Competitive Advantage, Book Chapter Morehead State University United States of American, vol. 58, pp. 16-31, 2013.

[205]Z. Xing, The impacts of Information and Communications Technology (ICT) and E-commerce on bilateral trade flows, International Econimics and Economic Policy, pp. 1-22, 2016.

[206]S. Xu, X., Munson and C. L. Zeng, The impact of e-service offerings on the demand of online customers, International Journal of Production Economics, vol. 184, no. 2, pp. 231-244., 2017

[207]X. Zhang, Impediments to e-commerce adoption as perceived by businesses, in Proceedings International Conference on Web Information Systems and Mining, Berlin, 2011, pp. 166-170.

[208] H. Zheng, A study on the usability of e-commerce websites between China and Thailand, International Journal of Simulation: Systems, Science and Technology, vol. 17, no. 1, pp. 34.1-34.4, 2016.

[209] M. Ziemba and E. Olszak, Building a regional structure of an information society on the basis of e-administration, Issues in Informing Science and Information Technology, vol. 9, no. 1, pp. 277-295, 2012.

[210]M. Zulueta, M. A., Cabrero and A. Bordons, Identificación y estudio de grupos de investigación a través de indicadores bibliométricos, Revista Española de Documentación Científica, vol. 22, no. 3, pp. 333-347, 1999. 